\title{
Skills for the 21st century: implications for education
}

Citation for published version (APA):

Allen, J. P., \& van der Velden, R. K. W. (2012). Skills for the 21st century: implications for education. Researchcentrum voor Onderwijs en Arbeidsmarkt, Faculteit der Economische Wetenschappen. ROA Research Memoranda No. 11 https://doi.org/10.26481/umaror.2012011

Document status and date:

Published: 01/01/2012

DOI:

10.26481/umaror.2012011

Document Version:

Publisher's PDF, also known as Version of record

\section{Please check the document version of this publication:}

- A submitted manuscript is the version of the article upon submission and before peer-review. There can be important differences between the submitted version and the official published version of record.

People interested in the research are advised to contact the author for the final version of the publication, or visit the DOI to the publisher's website.

- The final author version and the galley proof are versions of the publication after peer review.

- The final published version features the final layout of the paper including the volume, issue and page numbers.

Link to publication

\footnotetext{
General rights rights.

- You may freely distribute the URL identifying the publication in the public portal. please follow below link for the End User Agreement:

www.umlib.nl/taverne-license

Take down policy

If you believe that this document breaches copyright please contact us at:

repository@maastrichtuniversity.nl

providing details and we will investigate your claim.
}

Copyright and moral rights for the publications made accessible in the public portal are retained by the authors and/or other copyright owners and it is a condition of accessing publications that users recognise and abide by the legal requirements associated with these

- Users may download and print one copy of any publication from the public portal for the purpose of private study or research.

- You may not further distribute the material or use it for any profit-making activity or commercial gain

If the publication is distributed under the terms of Article $25 \mathrm{fa}$ of the Dutch Copyright Act, indicated by the "Taverne" license above, 


\section{Skills for the 21st century: Implications for education}

Jim Allen

Rolf van der Velden

\section{ROA Research Memorandum}

ROA-RM-2012/11

Research Centre for Education and the Labour Market Maastricht University

P.O. Box 616, 6200 MD Maastricht, The Netherlands

$\mathrm{T}+31433883647 \mathrm{~F}+31433884914$

secretary-roa-sbe@maastrichtuniversity.nl www.roa.nl 


\title{
Skills for the 21st century: Implications for education
}

\author{
Jim Allen \\ Rolf van der Velden
}

ROA-RM-2012/11*

July 2012

Research Centre for Education and the Labour Market

Maastricht University

P.O. Box 616, 6200 MD Maastricht, The Netherlands

$\mathrm{T}+31433883647 \mathrm{~F}+31433884914$

secretary-roa-sbe@maastrichtuniversity.nl

www.roa.nl

\footnotetext{
* The ROA Research Memorandum Series was created in order to make research results available for discussion, before those results are submitted for publication in journals.
} 


\section{Abstract}

\section{Skills for the 21st century: Implications for education**}

The world is changing rapidly in a lot of ways, but the dominant change is in ICT. Changing technology has far-reaching implications for how we act and interact at work, in education, in civic life and at home. Furthermore, this change is in large part the driving force behind many of the other major changes, such as globalization and flexibilization These changes have led many scholars to point to a new set of skills - the so-called 21st century skills - that are thought to be essential for people's ability to function and participate fully in today's world. While we do not dispute the importance of these 21st century skills, we do caution against blindly pursuing these skills and neglecting other more traditional classes of skill, such as basic skills (reading and math) as well as specialized knowledge and abilities - the so-called specific skills.

Educational policy and practice should proceed from the insight that skills of individual human beings form a complete interdependent package of all these three kinds of skills: basic skills, specific skills and 21st century skills. It is far more fruitful to view 21st century skills in relation to the basic skills that underlie them and the specific skills that they combine with in concrete purposive action.

In this essay we present a framework for the evaluation of what we know about our current situation in terms of various kinds of skills and learning which alerts us to gaps in our knowledge that need to be filled for future policy purposes. It also performs a similar function when looking at the challenges facing education and what education can do to meet these challenges.

JEL classification: 121, 125, 128, J24

Keywords: education, labour market, skills

Jim Allen

ROA

Maastricht University

P.O. Box 616

6200 MD Maastricht

The Netherlands

j.allen@maastrichtuniversity.nl
Rolf van der Velden

ROA

Maastricht University

P.O. Box 616

6200 MD Maastricht

The Netherlands

r.vandervelden@maastrichtuniversity.nl

** This essay is prepared on request of the Dutch Ministry of Education, Culture and Science and presented at a meeting of the Kenniskamer on April 11th, 2011 in The Hague. 


\section{Executive summary}

The world is changing rapidly in a lot of ways, but the dominant change is in ICT. Changing technology has far-reaching implications for how we act and interact at work, in education, in civic life and at home. Furthermore, this change is in large part the driving force behind many of the other major changes, such as globalization, flexibilization and the polarization of the job structure. Although we can hardly claim it is driving demographic changes, in combination demographic changes and ICT developments have much stronger effects than either would have alone.

These changes have led many scholars to point to a new set of skills - the so-called $21^{\text {st }}$ century skills - that are thought to be essential for people's ability to function and participate fully in today's world. While we do not dispute the importance of these $21^{\text {st }}$ century skills, we do caution against blindly pursuing these skills and neglecting other more traditional classes of skill. There is good reason to believe that general skills such as reading and math - the so-called basic skills - lie at the basis of the development of all other kinds of skills, including the $21^{\text {st }}$ century skills. We ignore this basis at our peril. In addition, the changes brought by ICT, globalization, etc. mean that the world has become a more complex place, with more complex technologies, organizational forms, and required knowledge bases in every sector of the economy than ever before. Dealing with such complexity requires correspondingly complex sets of specialized knowledge and abilities - the so-called specific skills. The application and development of $21^{\text {st }}$ century skills takes place in large part in combination with these specific skills, so again, we ignore them at our peril. Educational policy and practice should proceed from the insight that skills of individual human beings form a complete interdependent package of all these three kinds of skills: basic skills, specific skills and $21^{\text {st }}$ century skills. It is far more fruitful to view $21^{\text {st }}$ century skills in relation to the basic skills that underlie them and the specific skills that they combine with in concrete purposive action.

Existing schemes for classifying skills are useful because they give us a way of thinking about, discussing, evaluating and analyzing the otherwise hidden world of knowledge, talents, motivations and so on that every human being carries inside him/herself. However, classification often has the unintended consequence of focusing attention on just one dimension or one aspect of human skills, so we lose sight of the big picture of how the different dimensions and aspects of skills combine to form a coherent whole. 
Especially in the changing world of today where education is under pressure to accommodate a whole range of new skills next to the existing ones, we need a way of seeing where these new skills fit in. In this essay we present a framework for the evaluation of what we know about our current situation in terms of various kinds of skills and learning which alerts us to gaps in our knowledge that need to be filled for future policy purposes. It also performs a similar function when looking at the challenges facing education and what education can do to meet these challenges.

The Netherlands currently scores quite well in terms of basic skills, but there are indications that we are falling behind in terms of developing top talent. There is also a worrying trend towards lower scores over time in math, science and reading, especially for the younger age cohort. There is less evidence of where we stand in terms of $21^{\text {st }}$ century skills and specific skills, but we appear to do quite well in terms of problemsolving and less well in terms of civic competences. For ICT skills we do not as yet have any internationally comparable data. From Dutch research, it appears that young Dutch people have quite good medium-related ICT skills, but somewhat worryingly, perform much worse in terms of content-related ICT skills, which are much closer to the core of $21^{\text {st }}$ century skills. There is a large gap in our knowledge in terms of most $21^{\text {st }}$ century skills themselves, such as creativity, critical thinking, learning skills, sociocommunicative skills and self-management skills. There is some evidence for improvement in some of these areas, but stronger measures are clearly needed. In the absence of these we are left with the conclusion that the Netherlands generally performs quite well internationally in terms of producing skills, but there is some concern that we are falling behind in terms of top talent, and that our content-related ICT skills are less well-developed than our medium-related ICT skills.

There is a clear need for more information on other $21^{\text {st }}$ century skills and also on specific skills, and to continue monitoring basic skills via large-scale assessments. Recent initiatives to make use of new technologies to make large-scale assessments more continuous and authentic perhaps offer the promise that they can in time be integrated in a fruitful way directly into the learning process. The results of these initiatives warrant our close attention, but whatever their outcome is, it is clear that there is a need for more authentic, formative assessment methods in schools. There are already clear insights on the conditions under which formative assessment methods can 
be effective, but these need to be developed more in relation to new technologies currently emerging which create new possibilities and also new challenges in this area. It is far from clear that schools are equipped to deal with these challenges, raising the risk that what could be potentially a boon can end up as a burden on schools.

This applies not just to assessment, but to education in general. Within a very few years a tsunami of ICT is set to wash over education, and our education system is at present not fully equipped to deal with this. Young people are more ICT-savvy than their teachers, and ICT will enter the classroom whether we want it to or not. The problem is that the medium-related skills of young people are not well matched by content-related skills, and that teachers are currently not well placed to guide them in learning the latter type of skills. Nor are teachers currently sufficiently ICT-literate to make use of the enormous potential new technology offers in terms of interactive and iterative learning and assessment, open source content and the like.

In view of the huge challenges facing education in other areas, it is essential that schools make technology work for them, and certainly not against them. Demographic changes mean that student populations are becoming more diverse, and there is a need for a flexible response in dealing with strong individual differences in background, talent, culture and so on, and in choosing how to distribute the increasingly strained resources over the competing objectives of developing top talent, taking care of at-risk groups and all the while maintaining educational quality for the core group with middle-range abilities. Innovative learning environments have already been extensively implemented in Dutch education, but there is concern at the effectiveness of these methods if not administered appropriately. There is little doubt that such methods can be effective in fostering $21^{\text {st }}$ century skills in areas such as teamwork, communication and problem solving, but there is some concern that the conditions are not being met for these methods to be effective in developing basic skills, core subject knowledge and domainspecific skills. There is a need for learning models that more explicitly explain how these various types of skills can best be developed in relation to each other, what the optimal timing and learning sequence is, and - because education cannot do everything - what things have the greatest comparative advantage for development in education and which things can be best developed in other life spheres. It is of key importance that the insights into these conditions for educational effectiveness be updated to allow 
education to make optimal use of new developments in ICT. Here as well, it is important to teach the teachers, so that they are in a position to make effective use of the available tools and guide the process so that knowledge is acquired in a balanced way.

\section{Introduction}

The world is changing rapidly in a lot of ways, but we will argue in this essay that the dominant change is in ICT. Changing technology has far-reaching implications for how we act and interact at work, in education, in civic life and at home. Many of the other changes that have taken place in recent decades can be related to the increased importance of ICT, either because the changes themselves are partly driven by developments in ICT, or because the consequences of these changes has been strongly influenced by ICT. In addition to this, a number of new developments in ICT have direct consequences for the way in which education is organized.

These changes inevitably have important consequences for the set of skills needed in order for individuals to be able to function adequately in today's world, and to ensure growth, prosperity and social harmony in modern societies. More than ever before, the world is looking towards education to help prepare citizens to deal with the challenges presented by these changes. At the same time, education is facing other challenges of its own, such as the expansion of the higher education sector, the increasing pressure on educational budgets, the need to successfully implement innovative modes of teaching and learning, the need to balance the needs of the broad mass of students while still striving for academic excellence, and so on. In this essay, we present a framework for understanding the full range of skills Dutch education may be called on to provide, and develop some recommendations for how it can overcome some of the major obstacles it inevitably faces in pursuing its goals.

The outline of the essay is as follows. In Section 2 we will sketch the main changes going on in the world that are expected to have a direct or indirect impact on the skill requirements of the population. Following that, in Section 3, we look at various ways scholars have attempted to classify skills and competencies, and we will present a framework that combines the main elements of existing classifications. Section 4 summarizes the current state of knowledge about the state of the Dutch education 
system in terms of basic skills, civic competences, ICT literacy, educational attainment levels and drop-outs. Section 5 takes a look at some issues related to measurement and evaluation, both in large scale assessment surveys and at the level of schools. Section 6 sketches the main challenges education is facing, and Section 7 lists some recommendations as to the course of action that in our view needs to be taken. Section 8 summarizes our main conclusions.

\section{How is the world changing and how does this affect the skill needs of the population?}

The rapid changes going on in today's world present profound challenges for education systems. The changes are many and varied and affect both the demand and supply side of the labour market. We will start with the ICT revolution as this has also affected most of the other changes or has had an impact on their consequences. We will then continue with a number of related changes on the demand side of the labour market: globalization, flexibilization, and the polarization of the job structure. Next we will highlight the demographic changes that affect the supply side of the labour market. We will finish this section by highlighting the impact of these changes on the skill needs of the population.

ICT

Arguably the most important change of all has been in the upsurge in the development and usage of information and communication technologies at work and in day to day life. Many of the other changes that have taken place in recent decades can be related to the increased importance of ICT, either because the changes themselves are partly driven by developments in ICT, or because the consequences of these changes have been strongly influenced by ICT. More than ever before, the world is looking towards education to help prepare citizens to deal with the challenges presented by these changes. In addition to this, ICT developments have direct consequences for the way in which education is organized. Nowhere is it more important for education to come to grips with these challenges than in the Netherlands, with its open economy strongly weighted towards information-intensive services and its high internet density. 
The changes in the economy and broader society as a result of the rapid technological developments in recent decades are well documented. Voogt and Pareja Roblin (2010) point to the shift in emphasis from more factual and procedural knowledge to more conceptual and meta-cognitive knowledge as countries make the transition from an industrial to a knowledge society. In its recent Horizon Report, the New Media Consortium (Johnson et al., 2010) identifies key trends, challenges and technologies associated with the ICT revolution. The report focuses primarily on the direct impact of these developments for higher education, but much of what is contained in the report is relevant for other levels of education and indeed for the way people function in the economy and society as a whole. The authors point to the unprecedented range of resources and relationships that are easily accessible to anybody connected to the internet. As a result, people are increasingly expected to choose for themselves the timing and location for working, learning and studying. In addition, the technologies open up new opportunities for far reaching collaboration, whereby physical proximity of the collaborating parties is no longer a prerequisite. They point out the increasing importance of cloud-based technologies that do not presuppose that the user is aware of the physical location and configuration of the systems delivering the services, and the systems of decentralized IT support that accompany such technologies.

Looking towards the future, the authors of the Horizon report point to six technologies that are set to emerge in the next few years and which are expected to have important consequences for teaching, learning and investigative inquiry in general. In the short term, the authors expect developments in mobile computing and open content to have an important impact. Mobile computing refers to the hand-held devices most people already carry. The capabilities of the more advanced of these devices are rapidly rendering the term "mobile telephone" inadequate as a description. The widespread usage of such devices creates new opportunities for collaboration, flexibility and experimentation in learning and at work. There may also be a downside, in that the use of such devices may form a threat in terms of privacy, monitoring and control, as well as the possibility of a new digital divide between those who have access to such technologies and possess the skills to make full use of them and those who lack such access and/or skills. Open content refers to the increasing movement in education to take advantage of the almost unlimited availability of information on the internet rather than relying on in-house knowledge and source materials. Much of this is now highly 
formalized in the form of free online course materials that can be accessed by anybody anywhere in the world. Although the trend towards increased usage of open content in education has been stimulated by a desire to gain a grip on the rising costs of education and to provide access to learning for those in areas where such access is otherwise difficult, it is important to remark that this development has tremendous positive potential for education, and that its popularity is also a reflection of student choice as well as educators' convenience. For the first time in history, it will in principle be possible for every student to follow courses developed and sometimes even presented by the most distinguished scholars in the world.

The Horizon report points to two technologies expected to play a significant role in the mid-term, that is in the next two to three years. These technologies are in the use of electronic books and of simple augmented reality. Although electronic books have been available in some form for several decades already, the authors point out that recent developments in reading devices opens up new possibilities for acquiring, storing, reading and annotating documents, making it possible for people to travel with a virtual library and to use the information in a highly flexible way. As for simple augmented reality, whereas traditional devices were unwieldy and usually required the user to be tied to a fixed computer and use cumbersome headsets and the like, the cameras and monitors in modern mobile devices enable their users to easily combine real world and virtual data, using such things as GPS and image recognition software to overlay the real-world image on the screen with useful data on the objects portrayed. A little further down the road, but still likely to be implemented on a widespread basis within some four to five years, gesture-based computing and visual data analysis are likely to radically change the way we interact with computers to control applications and interpret data.

\section{Globalization}

For the first time, the marketplace which graduates enter after leaving education has become truly global, and the firms and organizations for which graduates work have become increasingly international in their orientation. As a recent series of articles by BBC online (Schifferes, 2007) makes clear, the trend towards globalization of the economy is inextricably linked to technological developments such as those described above. Globalization as a phenomenon dates back at least to the 1950s, but under the 
influence of developments in ICT (as well as of the liberalization of trade and finance, which in turn has also benefited from the vastly increased possibilities for storage and transfer of information made possible by the ICT revolution) the process has increased dramatically in pace and scope in recent years. The falling costs of transport and communication and the increasing tendency for consumers and retailers to buy on a global rather than local market have led to dramatic changes in production processes. Companies use the internet to manage both their supply chain and their support services, in many cases outsourcing the latter to third world countries like India with cheap but nonetheless well educated workforces. Information technologies are also a major driving influence behind the liberalization of capital markets. Predictably, such developments have a major impact on the demands made on the workforce in countries like the Netherlands. In many cases Dutch companies and Dutch workers are experiencing direct competition from comparable companies and workers in other countries, and are being forced to find new ways to compete. No longer is it sufficient to fall back on a relative monopoly of local knowledge, it is becoming increasingly important to compete through access to global knowledge. The speed of the developments and the adjustments that are necessary require much greater flexibility.

In addition to the effects of globalization on the economy forcing a fundamental rethinking of the set of skills needed by the workforce in a country, globalization is having a direct effect on education, particularly higher education, and much of this is also driven by the ICT revolution. A recent OECD report (2009) points to the increased trend towards globalization of the market for higher education, and predicts a growing international mobility of students, faculty and institutions. Although this mobility as such is not directly based on ICT developments, it would not be feasible without the access to information on education institutions throughout the world that is now freely accessible to everyone through internet. Similarly, academic research has seen, and is likely to continue to see, an increased trend towards international collaboration and competition. In both education and research, there is a trend towards decreased dominance by North America and an increase in influence of Europe and particularly of Asia. Increased world-wide competition has led to, and will continue to lead to, a trend towards more market-based thinking in education, and has contributed to an erosion of boundaries between public and private education. 


\section{Flexibilization}

The simple fact that the world is changing so rapidly requires a much greater degree of flexibility on the part of workers and of citizens at large than hitherto was the case. This need to be flexible is made more urgent by virtue of the nature of the changes involved. The shift from an industrial to a knowledge society requires people to deal less with objects, machines, materials and so on which are by their nature relatively fixed, at least over short periods of time, and more with ideas, concepts, insights, and so on that can change on time scales of days, hours or even minutes. This requires a high degree of functional flexibility at work and in daily life. In addition, the unprecedented level of interconnectivity made possible through the internet and in particular by the plethora of hand-held mobile devices currently or soon available effectively means that people are increasingly expected to conduct their daily business at any time and in any place: in the train, while driving their car, or in their free time. This inevitably blurs the dividing line between work and private life. Moreover, at work it is becoming increasingly difficult for people to withdraw into the relative peace and quiet of their own office or workroom, since they can be contacted at any time by clients, colleagues and others with requests, suggestions, advice or complaints. Within private life the dividing line between time traditionally reserved for family and loved ones and time spent on recreational activities outside the home, civic life and the like has also become fuzzier. All of this places heavy demands on individuals' ability to manage their time in a flexible yet ordered manner. In education, new technologies such as mentioned above create enormous opportunities for innovation, but this will inevitably also lead to a high required level of flexibility on the part of both educators and students in order to cope with the additional layers of complexity and choice that are becoming available. Ignoring these changes is unlikely to be an option: most of these technologies will enter the classroom whether invited or not.

Globalization and the associated trend towards stronger competition in the economy also demand a highly flexible response by entrepreneurs, managers and employees. In a global marketplace, the criteria for success or failure can change from one day to the next. Also under influence of changing technologies, skills that used to be highly valued become obsolete, the content of jobs changes, new jobs are created while old jobs are abandoned, new firms replace old ones that have closed or gone bankrupt, and entire new industries are arising while old ones are disappearing onto the dust heap of history. 
Although it would probably be unduly alarmist to suggest that long-term work contracts will become a thing of the past, most people will need to adapt their career plans on a more or less continuous basis, and even those who remain employed in the same firm for a long period of time will need to be able to adapt to a changing package of work tasks. In addition, as a result of greater global interconnectivity, people will increasingly find themselves collaborating with colleagues who are not in the same physical location, but may be in a different branch or partner company in a different part of the country or even on the other side of the world. This adds an additional dimension to flexibility, namely the ability to adapt to different and changing (corporate) cultures. In education, the increased trend towards globalization of the market for education (in particular higher education), means that teachers are increasingly expected to deal flexibly with a much more culturally diverse student population than was previously the case.

\section{Polarization of the job structure}

Levy (2010) points out how computerisation has changed the content of work tasks. The logic is that all routine tasks can be expressed in simple rules. Manual routine tasks can therefore be performed by robots (mechanisation) and routine cognitive tasks can be performed by computers. Some tasks can also easily be outsourced to low wage countries. This leads to a polarisation of the job structure, with a growth in jobs that involve high level expert thinking and complex communication, a gradual decline in the share of jobs that involve non-routine manual tasks and a sharp decline in routine manual and cognitive tasks. This polarisation sharply affects the number of jobs in the middle of the earnings distributions, like clerks, assembly line workers, and other jobs that mainly involve routine tasks. The following figure shows how the middle tercile has decreased in the period 1993-2006. 
Figure 1

Change in employment shares by occupation in EU and US, 1993-2006

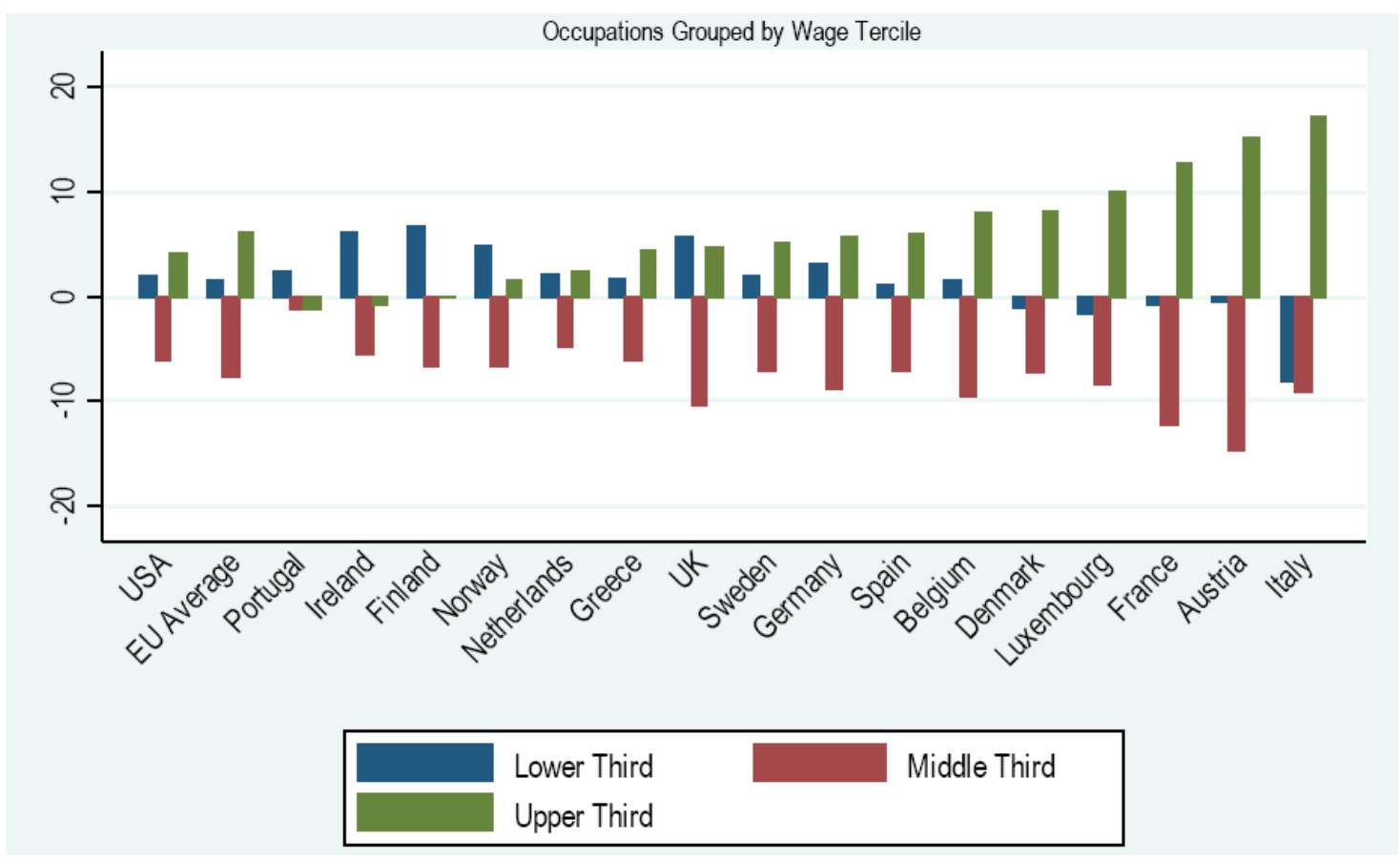

Source: Autor (2010), adopted from Goos, Manning and Salomons (2009)

\section{Demographic changes}

The previous changes were all related to the demand side of the labour market. But there are also a number of demographic trends that have a major impact on the supply side of the labour market and are likely to have an impact on education systems throughout the world. Most western countries experience major demographic changes, as populations have become relatively older and more culturally mixed. This has been accompanied by changes in social attitudes, with a tendency towards more individualization often placing pressure on social cohesion and solidarity. Especially the ageing of the working population has profound effects on overall skill levels. Most cognitive abilities such as memory function, information processing speed and attentional capacity tend to decline with advancing age. The following graph shows for the Netherlands how the level of literacy and numeracy skills declines with age. 
Figure 2

Changes in literacy and numeracy skills over the life course
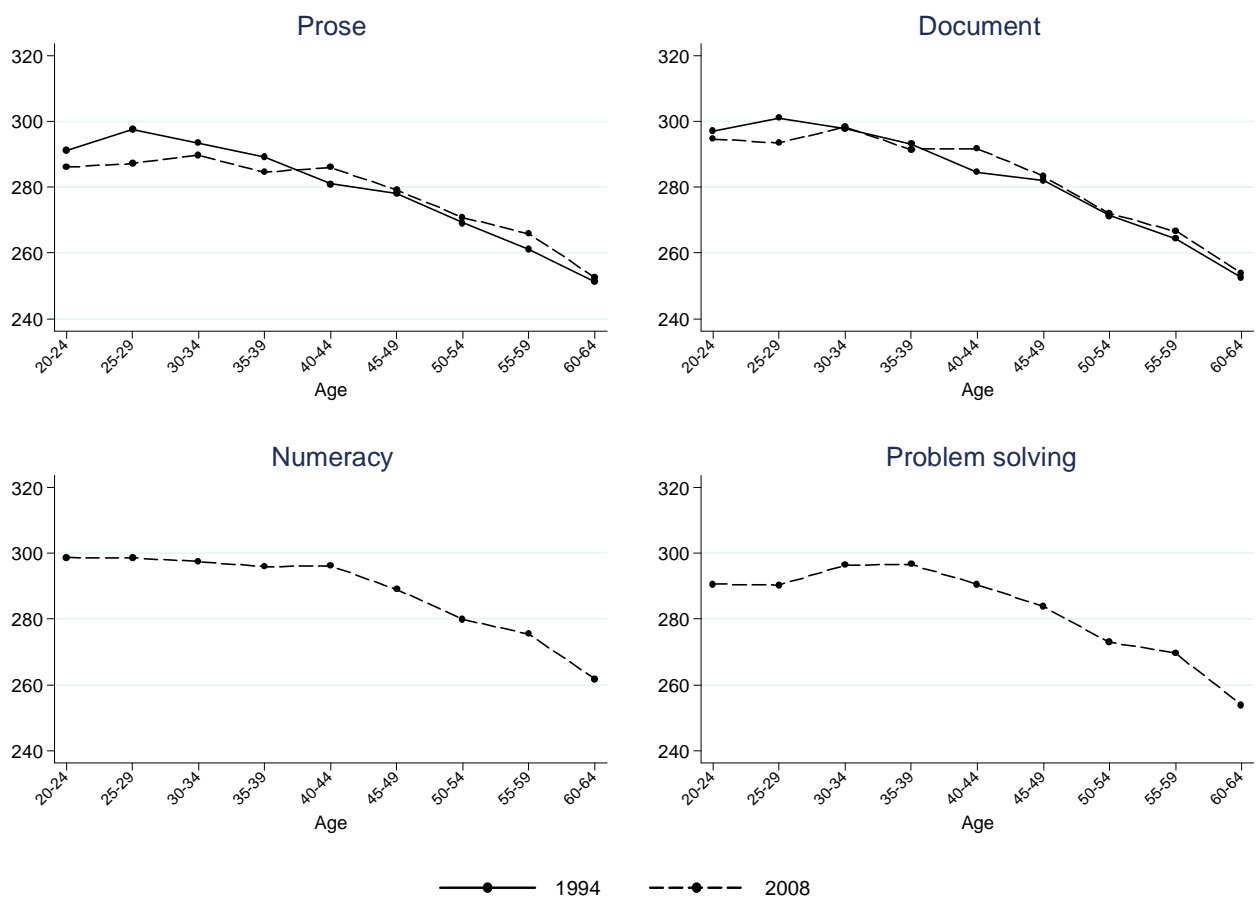

Source: IALS and ALL, own computations (see Fouarge and De Grip, 2011)

The single most important finding of IALS and ALL was that skill loss related to ageing was sufficient to offset all of the expected gains from increasing educational quality and quantity (Murray et al., 2005). Until now, only scattered studies on different aspects of skills obsolescence have been published. Most of these studies were published in periods in which unemployment was high. This increased the focus on the adverse impact of skills obsolescence for the workers involved. It is interesting to note that in recent policy debates on skills obsolescence and 'lifelong learning' the main focus has shifted to the waste of valuable human resources and the sub-optimal performance of workers with inadequate skills. This brings skills obsolescence to the heart of the debate on the main economic challenge western economies face: realizing the transformation towards a knowledge-based society with an ageing population. 
As Voogt and Pareja Roblin (2010) make clear, the shift from an industrial society to an information and knowledge society has far-reaching implications for the kinds of skills needed by the workforce and the population at large. This shift was already noted in the early 1990s by Reich (1992), who remarked on the increased need for both knowledge and socio-communicative skills. Voogt and Pareja Roblin assert that although the changes are taking place in widely differing sectors of the economy, there is a common set of core " $21^{\text {st }}$ century skills" that are needed in virtually all domains, comprising cooperation, communication, ICT literacy, and social and/or cultural skills, creativity, critical thinking and problem-solving skills. Some models studied by them also referred to learning skills, self-management, planning, flexibility, willingness to take risks, metacognitive skills, entrepreneurial skills, as well as core subjects at school (such as math, language and science) and interdisciplinary thinking. These are the skills that according to many are needed in order to function adequately in, and make a useful contribution to, the knowledge and information society in the $21^{\text {st }}$ century.

While the importance of these $21^{\text {st }}$ century skills is indisputable, it is important not to lose sight of the fact that other skills are needed as well. The OECD (Thorn, 2009, see also Murray et al. 2005; Schleicher 2008) in particular has emphasized the importance of general basic skills such as literacy and numeracy for the chances of success at work and life in general for individual citizens, as well as for the social and economic wellbeing of nations. Furthermore, as we will argue below, there is good reason to believe that such basic skills lie at the basis of the development of all other kinds of skills, including the $21^{\text {st }}$ century skills. At the same time, the increasing complexity of the world has led to a huge increase in the importance of the highly specific skills that are needed in order to be able to function in particular economic domains. The concrete development and application of $21^{\text {st }}$ century skills takes place in large part in combination with these specific skills.

Educational policy and practice should proceed from the insight that skills of individual human beings form a complete interdependent package of all these three kinds of skills: basic skills, specific skills and $21^{\text {st }}$ century skills. It is far more fruitful to view $21^{\text {st }}$ skills in relation to the basic skills that underlie them and the specific skills that they combine 
with in concrete purposive action. Before addressing the question of what education can do to achieve these aims, it is useful to look a little more closely at the nature of these various skills and the manner in which scholars from various disciplines have attempted to classify them.

\section{A heuristic scheme for the classification of skill requirements in the $21^{\text {st }}$ century}

There are few topics in the social sciences that have received more attention in recent years than that of the classification of knowledge, skills, abilities, competencies and the like. It is emphatically not the aim of this essay to provide a comprehensive overview of the literature on this topic. Our aim is more modest, namely to provide a brief analysis of what the purpose of such attempts at classification are, and to point out ways in which a balanced model taking account of the main concepts and dimensions covered by the literature can be used to guide educational policy, in particular in relation to the trends described in the previous section. We start by making a simple and rather obvious observation, namely that all typologies, classifications, skill dimensions and so on are in fact artificial constructs thought up by scholars, which only correspond roughly to the much more fuzzy reality of the many and diverse ways in which people can be "good at doing things". In real living human beings, the knowledge, skills, and so on that they possess do not allow themselves to be bundled into convenient parcels, but are much more like localized accents or emphases in the interrelated whole of what people are capable of. For example, when we distinguish between, say, generic and specific skills, we conveniently ignore the fact that even the most "specific" of skills such as the ability to use advanced engineering software or to perform brain surgery involves the use of some very generic abilities such as the capacity to weigh different options for action and to act decisively even in case of doubt. Conversely, even generic skills such as analytical thinking are not applied in a substantive vacuum, but are used to assist decision making and guide action related to highly specific contexts, and are usually based on an existing body of specific knowledge related to those contexts. This realization does not render existing classifications and typologies meaningless, but does make us aware that they are nothing more or less than convenient constructs that allow us to structure our discussion and study of skills. 


\section{Specific and generic skills}

The above-mentioned distinction between specific and generic skills is one of the most basic distinctions that can be drawn, and has been used and developed extensively in the social sciences in recent decades. Like most typologies, it is also often subject to ambiguity and confusion. Human capital theorists such as Becker (1962) have drawn a distinction between firm-specific and general human capital in order to derive predictions related to the division of costs and benefits related to training in both types of capital. The idea behind this is that general human capital can be productively used in any firm or organization, suggesting that the costs of obtaining such knowledge and skills should be borne by the worker involved, whereas the relative uselessness of firm-specific human capital outside the firm in question implies that at least part of the costs should be borne by the firm. To this dichotomy can be added a third category, namely that of occupation-specific or domain-specific human capital, which can be applied in different firms or organizations, but only within a relatively narrow range of work tasks. In debates related to the Dutch education system with its extensive vocational components in both secondary and tertiary education, it is this latter meaning that is usually referred to when the term "specific skills" is used.

There is no need for us to delve too deeply into this discussion here, but a few observations are nonetheless pertinent to this essay. First of all, we wish to point out that discussions relating to 'basic skills', ' $21^{\text {st }}$ century skills', 'key skills' and such are heavily focused on generic skills, whereby a danger exists that the importance of highly specific knowledge and skills for functioning in work and everyday life will be underestimated. In the words of the German psychologist Weinert: "Over the last decades, the cognitive sciences have convincingly demonstrated that context-specific skills and knowledge play a crucial role in solving difficult tasks. Generally, key competencies cannot adequately compensate for a lack of content-specific competencies" (Weinert, 2001: 53). A second point to be made relates more directly to the above-mentioned trends, and more specifically to the fact that is that in a rapidly changing world specific skills can quickly become obsolete. At first sight this may appear at odds with the first observation, and suggest that specific skills are by nature transient and therefore not important, but this is not what we are suggesting. We rather point to the fact that the ability to acquire, refresh and update specific skills is becoming increasingly important. As many have pointed out, 
this underscores the importance of acquiring learning abilities as a way of dealing with the changes going on in the world. While we agree with this, we would add to this a third observation, often neglected in such discussions, namely that even when it has become obsolete, pre-existing specific knowledge and skills are often a prerequisite for learning new specific knowledge and skills. In turn, these reflections have implications for a fourth observation, that is that the dividing line between what is learned in formal education is subject to ongoing negotiations involving representatives of all major categories of stakeholders, including educational institutions, students, firms and organizations, employees and government. By this we mean that generic skills are not the exclusive domain of education, but can be developed outside education as well, and conversely, that occupation-specific skills and even firm-specific skills may enter the arena of formal education.

Innate abilities and learnable skills

A second dichotomy is also important in relation to the discussion of the role of education, and that is the distinction between innate abilities and learnable skills. Like the distinction between specific and generic skills, it is somewhat misleading to view this as a strict dichotomy, since few skills can be placed neatly into one category or the other. Although the discussion of innate abilities is still somewhat controversial in some areas, these days most would agree that at least some individual differences in knowledge and skills are ultimately traceable to a biological or genetic source, and this applies more strongly to certain kinds of abilities than to others. However, it is equally difficult to identify areas of skills that are totally impervious to attempts to develop them further. In practice, it is more realistic to say that skills differ in the extent to which they can be learned. Like specific skills, the question of the extent to which attention is paid to learning different kinds of skills in education is not one that can be answered in a black and white way, but is likely to remain the subject of ongoing debate, taking account of the fact that all educational decisions involve a trade-off between different possibilities under conditions of limited resources. 


\section{Crystallized and fluid abilities}

Another relevant distinction is that between so-called crystallized and fluid abilities (see for example Murray et al., 2005). The latter refers to functions that involve controlled and effortful processing of novel information (cognitive mechanics), and the former to the representation of learned skills and access to knowledge (cognitive pragmatics). Crystallized abilities, otherwise known as the accumulated knowledge base (Carroll, 1993), refer to such things as language development, comprehension and lexical knowledge. Fluid abilities refer to reasoning abilities used to draw connections between concepts, to understand implications, to arrive at conclusions and so on.

The two abilities show markedly different patterns of development and decline over the life cycle (see Figure 3). Fluid abilities are far more sensitive to ageing. Fluid abilities typically start declining when people are in their mid twenties, while crystallized abilities may improve until and beyond even the age of seventy. The two most prominent symptoms of 'usual' cognitive ageing in daily life are a gradual reduction in memory retrieval and information processing speed. Stored information remains relatively intact, but access and retrieval becomes increasingly difficult for older individuals. Another feature that has received considerable interest in research is the reduced ability of older individuals to suppress or inhibit irrelevant information, making decision processes more complicated, and therefore slower.

The distinction between the two classes of abilities is important because the rapid changes driven by the ICT revolution will require that adults are able to update their skills on a regular basis and engage in lifelong learning. The success of the learning experiences later in life will depend strongly on their fluid abilities and for adults, the decline in fluid abilities is more likely to strongly hamper their working and everyday life than the decline in crystallised abilities. 
Figure 3

Theoretical representation of 'crystallised' and 'fluid' abilities over the life span

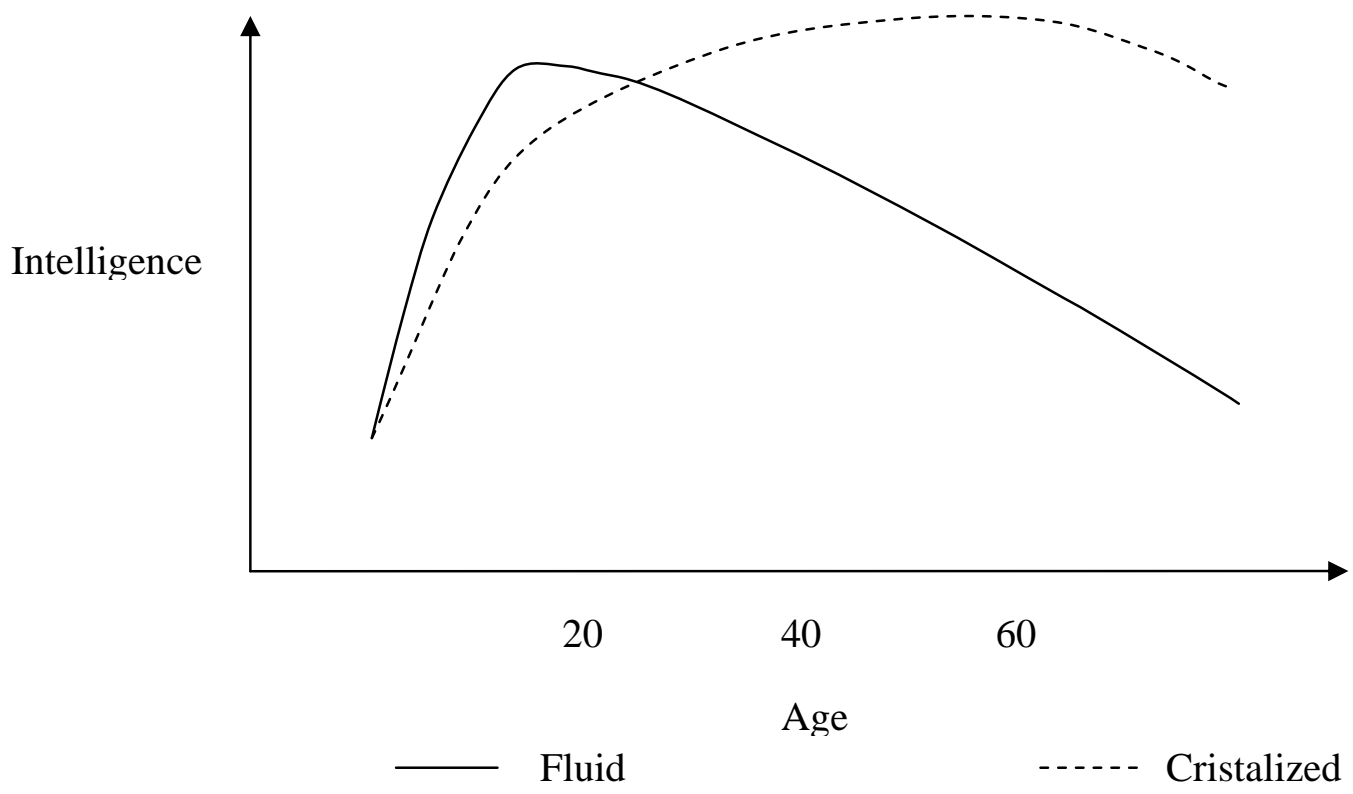

Source: based on Cattell, 1987

Basic and advanced skills

The key focus of most international studies of skill levels of the population, whether they be surveys of school-aged students (e.g. PISA, TIMMS) or of the working age population (IALS, ALL, PIAAC) has been on assessing levels of so-called basic skills (Thorn, 2009; Murray et al., 2005). These are skills such as literacy and numeracy skills that, although not sufficient to guarantee success in the workplace and in life in general, are thought to be certainly necessary, and to form in large part the basis for the development of other, more advanced skills.

The dichotomy can in our view be quite misleading. Juxtaposing the terms "basic" and "advanced" when referring to skills may give the erroneous impression that "basic" skills are by definition low level skills. Although it is true that a basic command of these skills is a prerequisite for functioning in most areas of life, it will be clear that it is perfectly possibly to possess these skills at a highly advanced level, as any PhD holder in mathematics or linguistics can tell us. The term "basic" seems rather to refer to the fact 
that these skills in large part lie at the basis of applying and developing skills in other areas, and also that they are essential skills in any environment. In that sense it is better to use the term key skills instead of basic skills.

\section{ICT skills}

There is a strong case to be made for adding ICT skills to this list of basic skills, given the pervasiveness of ICT in our work and everyday lives. It could be argued that in the future the ability to successfully use ICT will be just as essential for our ability to function in society as the ability to read, write or count. However, it is worth noting that what is commonly referred to as ICT skills cover a range of activities that go from highly specific to almost completely generic. Van Dijk (2005) distinguishes between operational ICT skills (skills directly related to the development and application of ICT hardware and software), ICT information skills (skills related to searching, selecting and processing information on computers, the internet and other ICT media), and strategic ICT skills (skills related to using ICT to achieve specific or more general goals). ICT information skills are further divided by Van Dijk into formal information skills (skills related to the formal structures and forms in which information is made available, such as file or menu structures, hyperlinks and so on) and substantial information skills (skills related to finding, selecting, processing and evaluating substantive information). This classification may be slightly too limited to describe current ICT practices, but if we extend the description of information and strategic skills to include interactivity, communication and transmission as well as retrieval of information, it is still broadly sufficient. Although basic operational ICT skills are necessary skills for everybody, it is clear that advanced levels of such operational ICT skills are only likely to be needed by a relatively small proportion of the population. Some of these skills are so highly specialized that they can only be learned through long periods of intensive training. Such skills are in that respect comparable to other technical and engineering skills, for which specialized programmes of education and training exist. This is different for formal ICT information skills, which are largely non-technical, but nonetheless require a considerable familiarity with the technologies in question. The description of this category should be extended to include practical familiarity with the latest mobile technologies. It could certainly be argued that this class of ICT skills is rapidly becoming a basic skill one needs to master for full participation in the economy and society. Such skills take appreciable time and effort to 
master. Even comprehending a relatively simple concept such as a "tweet" presupposes a basic knowledge of the structure of the internet, mobile communication technologies, text messaging, and so on, as well as of the social codes, expectations and etiquette surrounding the use of such forms of communication. By contrast, substantial ICT information skills and strategic ICT skills involve a wide range of generic skills such as logical reasoning, deductive reasoning, an ability to distinguish between fundamental points and side issues, evaluating the trustworthiness of different information sources, and so on, that, while in no way specific to ICT, have been rendered more important due to, and arguably also qualitatively changed by, the complex challenges thrown up by the ICT revolution.

\section{Skills and competencies}

Another distinction that is useful to mention is that between skills and competencies. The more or less definitive work in this area is that done in connection with the DeSeCo (Definition and Selection of Competencies) project, which was initiated by the OECD to provide an overarching framework to international skills assessments. The main results are contained in the report "Key Competencies for a Successful Life and a Wellfunctioning Society" (Rychen and Salganik, 2003). Emphasising the need for competence assessment rather than a narrow focus on skills, competencies are defined in this project as: "the ability to successfully meet complex demands in a particular context through the mobilization of psychosocial prerequisites (including both cognitive and non-cognitive aspects)" (Rychen and Salganik, 2001, p. 43). The basic difference with the earlier concepts of skills is the holistic nature of the concept of competence. It refers not only to a range of cognitive and non-cognitive skills and other prerequisites that need to be in place in order to perform in a competent way, but also to the notion of 'orchestration', the ability to use these constituent elements in a meaningful and deliberately arranged way. In that regard, the 'whole' that makes up a competence is more than just the 'sum of its parts'. Skills can therefore best be considered as one of the constituent elements of a competence. The project identifies three categories of key competencies, namely interacting in socially heterogeneous groups, acting autonomously, and using tools (such as literacy, numeracy etc) interactively. The transversal feature cutting across these three categories of key competencies is 
reflectivity, the ability to make independent judgments and take responsibility associated with higher levels of mental complexity.

\section{$21^{\text {st }}$ century skills}

The concept of " $21^{\text {st }}$ century skills" combines aspects of several of the above mentioned dimensions and typologies. Voogd and Parjea Roblin (2010) define $21^{\text {st }}$ century skills in terms of the ability to perform tasks for which it is necessary to interpret complex patterns, in which people cannot be easily replaced by computers (such as may be the case for many routine production processes), but in which the human operators can be supported by information generated by computers. Using examples such as the truck driver who must find the way to deliver goods and the physician diagnosing a patient, the authors make clear that there exists a set of skills which are relevant for a wide range of work. The authors point out that other terms, such as lifelong learning competencies and key skills are often used to refer to basically the same set of skills. Based on an analysis of 32 documents they concluded that skills related to cooperation, communication, ICT literacy, and social and/or cultural skills were common to all models. In addition, most models referred to creativity, critical thinking and problem-solving skills. Some models referred to learning skills, self-management, planning, flexibility, willingness to take risks, metacognitive skills, entrepreneurial skills, as well as core subjects at school (such as mother language, foreign languages, math and science) and interdisciplinary thinking. It is odd to note that, despite the globalisation, foreign language skills does not appear in all documents as a $21^{\text {st }}$ century skills. This is probably a reflection of the fact that many documents have an Anglo-Saxon origin.

In terms of the dimensions described above, most if not all of these skills can be described as generic, mainly fluid rather than crystallized, and advanced as opposed to basic (with the possible exception of ICT literacy and core school subjects). Although the authors use the Dutch equivalent of the term competencies to refer to these skills, it is not clear whether they are referring to competencies in the holistic manner referred to by Rychen and Salganik (2001, 2003). 


\section{Can the existing concepts be combined into a coherent framework?}

One of the main obstacles to developing a coherent framework for the full range of skills and competencies people may need in their work and daily life is the very different manner in which different scholars approach the subject. Many researchers are mainly driven by practical considerations, namely the need to develop a typology that can be used to describe what is going on in a particular setting, such as a firm or a school class. Such approaches often yield typologies and classifications that are rich in concrete detail, but somewhat lacking in theoretical underpinnings. Other approaches are much more interested in deriving insights relevant for a fundamental understanding of the nature of skills, competences and cognitive function of people, but are too abstract to be directly applicable in a practical setting. Murray et al. (2005) developed a framework that combines insights from both practical and more fundamental research, and that also provides a useful summary of many of the concepts and dimensions described above. This work concentrated on two strands of research: research on what skills are necessary in the workplace, and research on cognitive functioning. From the first strand a list of six skill areas were extracted that seemed to underlie many of the most important skills: Communication (speaking, listening, reading, and writing), Mathematical, Problem Solving, Intrapersonal (motivation, metacognition), Interpersonal (teamwork, leadership) and Technology. From the strand of psychological theory four core domains of intelligence were extracted: practical abilities, crystallised analytical abilities, fluid analytical abilities, and creative abilities (the ability to cope with novelty). As the authors point out, the two strands are not mutually exclusive, but rather represent different aspects of skill. The workplace skills provide the context within which each of the four core intelligence domains are expressed; or, conversely, each category of workplace skill can involve four distinct types of thinking.

The two dimensions can be combined in the following pyramid (Murray et al., 2005). At the lowest level of the pyramid they place basic skills related to numeracy and literacy, as well as to oral communications, learning ability and self-management skills and motor skills. Of these, certainly oral communications skills and learning ability would be classed as $21^{\text {st }}$ century skills and the others as basic skills. These skills are described as fully portable, i.e. generic. According to the scheme, the middle level consists of skills that presuppose the existence of a solid basis of the basic lower level skills, providing a neat 
illustration of the concept of basic in the sense of "providing a basis for" rather than of "elementary". This basis can be viewed as a "gateway" that opens access to the broader world in which the higher-level skills must necessarily be learned. For the most part the middle levels skills would fit the description of $21^{\text {st }}$ century skills. These skills are described as largely portable or generic, but are closer in their description to actual concrete work tasks - albeit relevant to a wide range of work settings - than are the basic skills. They include interpersonal skills like teamwork, analytical and problemsolving skills and technical skills like ICT. Finally at the top we find the firm- and jobspecific bodies of knowledge that are clearly only portable to a limited extent and as such are specific rather than generic. These skills depend for their development and use on the levels below them, and thus are dependent in part on basic skills and $21^{\text {st }}$ century skills.

\section{Figure 4}

Skill supply and demand by context

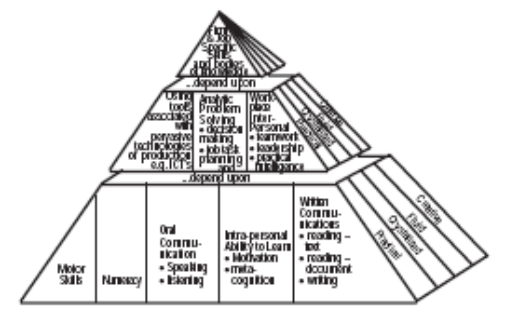

The Community

- Consumer markets

- Health

- Citizenship

- Culture

- Education

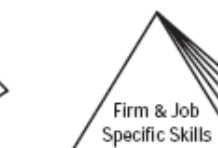

Narrowly

Portable

and bodies of

knowledge

...depend upon

Analytic Problem

\begin{tabular}{l|l} 
Usingtools & Solving \\
associated & $\bullet$ decision making
\end{tabular}

associated - decision making Inter-Pers

with pervasive - job task planning. teamwork

technologies and organizing - leadership

of production - significant use - practical

e.g. ICT's of memory intelligence ...depend upon

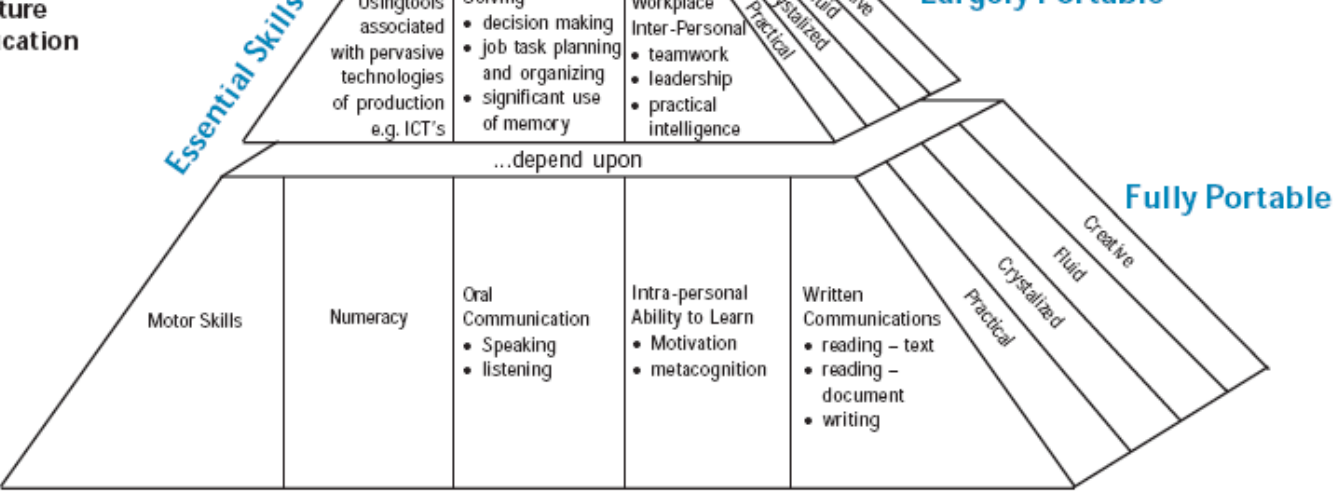

The World of Work

Home Environment

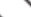

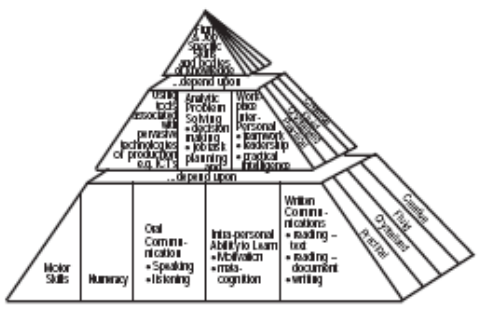

- Family • Culture

Health

Largely Portable 
Like all of the classifications described above, this diagram is a simplified construct that only roughly corresponds to the real world. Its usefulness lies in its provision of a heuristic framework for thinking about and discussing skills. It contains, at least implicitly, most of the important dimensions referred to in classification systems such as described above, and illustrates how these form an interrelated whole. It illustrates the point that certain kinds of skill are more basic or fundamental, and that other types of skill build upon these basic skills or at least depend upon them in their application. This idea provides us with a useful way of conceiving of, for example, the interrelatedness of specific and generic skills described above. Specific skills consist of highly contextspecific or domain-specific knowledge, abilities and so on that often depend upon more basic skills (reading, writing, motor skills) or generic skills (analytical skills, cooperation) for their successful application. The diagram makes clear that all levels and within levels for all categories of skills a further distinction can be drawn between crystallized and fluid abilities, to which the authors add practical and creative abilities to show the full range of skills involved. They themselves illustrate the distinction using as an example linguistic intelligence: reading a short story would invoke crystallized linguistic skills, analyzing the content would bring fluid abilities into play, thinking of a way to apply the insights gained to everyday life would make use of practical abilities, while finally, thinking up new variations to the ending or devising one's own story along similar lines would be an example of applying creative linguistic skills. Another important feature of the diagram is that it shows that there are comparable and conceptually equivalent pyramids that can be drawn in different life domains, such as those of work, home life and the community at large. Although it is this feature of the diagram that is most artificial - as we noted above, the dividing lines between these domains are becoming increasingly fuzzy, and in any case there will be considerable overlap in the skills used in each domain - it is useful to draw this conceptual distinction, because it draws our attention to the fact that the skills required of citizens in today's complex world need to form a "complete package" as it were in all three of these domains.

The usefulness of such a representation is in our view twofold. First, it encourages us to look at skills not as isolated entities but as things that are developed and applied in combination with and in relation to other skills. This comes close to a practical application of the ideas developed in a highly abstract manner by the DeSeCo group and helps us understand where typical $21^{\text {st }}$ century skills fit in the overall picture in relation to 
more basic skills on the one hand and specific skills on the other. Secondly, at the same time it alerts us to the fact that precisely when it comes to this interconnectedness and interdependence between a wide range of skills, there are still large gaps in our knowledge. Particularly in terms of insights into skill development in education, skills are sometimes conceived of too simplistically as bundles of cognitive potential that can be learned by anybody in any order at any time in their life, thus reducing the choices confronting education as simply one of deciding which skills to devote educational resources to. As we will argue below, the challenge facing education is far more complex than this.

\section{How well does Dutch education prepare for the skills that are needed in the $21^{\text {st }}$ century?}

In Section 2 we have described how the world is changing and what this implies for the skill needs of the population. In this section we present an overview of what we know about the extent to which the Dutch educational system supplies these skills. Is the Dutch system currently supplying the skills that the modern knowledge economy requires?

\section{Basic skills}

A recent review on the quality of Dutch education (Scheerens, Luyten and Van Raven, 2010) paints a rather positive picture when it comes to basic skills. Using international data on math, language and science tests for students from primary and secondary education (TIMMS, PIRLS and PISA), Luyten (2010) shows that according to most ranking systems the Netherlands performs quite well, especially in math. They rank among the top 5 when only European countries are included and among the top 10 when all countries are included. These results are confirmed when we look at the data for the adult population IALS and ALL. There are however two caveats.

The first is that average scores tell only part of the story. It is also important to know how countries perform across different parts of the skills distribution. It turns out that the Netherlands' high ranking is largely due to its having very good scores in the lower part of the skills distribution. However, it scores less well when we look at - say - the top $5 \%$ 
of the skills distribution. This is well illustrated by the results shown in Figure 5 from the ALL survey. For the lowest $5 \%$ and $25 \%$ of the skills distribution, the Netherlands has the highest scores, together with Norway. But for the top 5\% the Netherlands shifts more towards the middle. This confirms the earlier findings by Minne et al. (2007) that the Netherlands is doing less well in developing top talent. According to this study, the Netherlands drops out of the top ten when we look at the performance of the $99^{\text {th }}$ percentile, the top $1 \%$ of the students.

\section{Figure 5}

Literacy scores across the skills distribution, 16-65 year olds

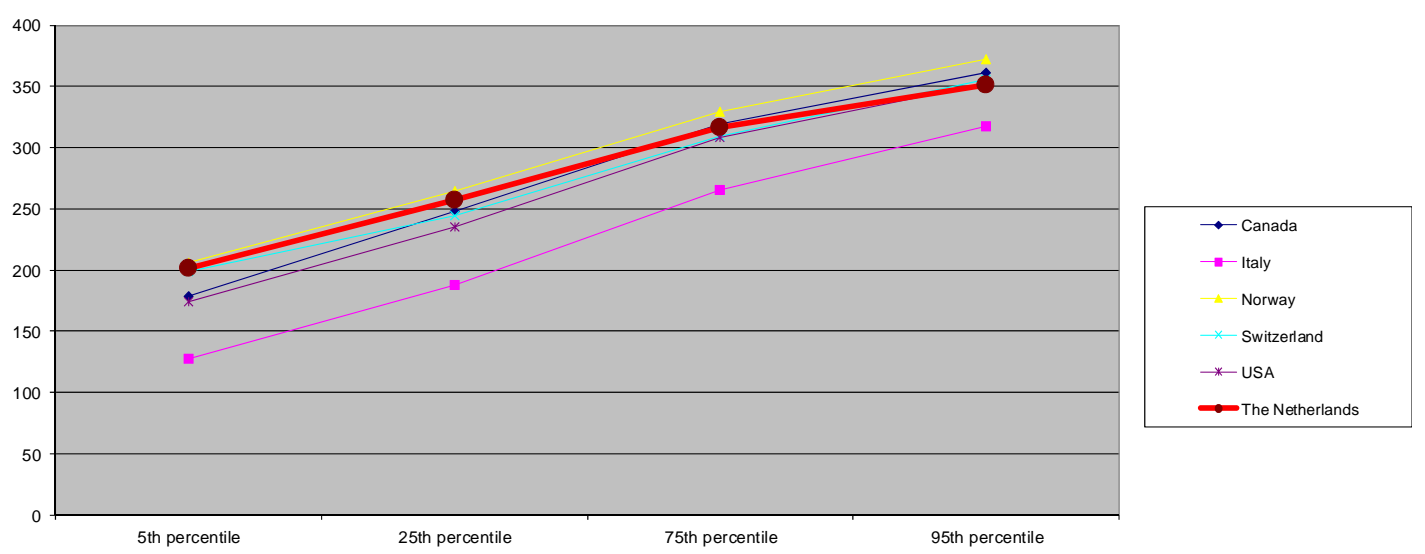

Source: ALL, own computations

The second caveat is that there are indications of a downward trend in the test results for the Netherlands over time, at least compared to other countries. Not all of these differences are statistically significant, but most point in the same direction: a negative trend in the scores for math, science and reading, especially when a longer time period is taken into account. 
Figure 6

Change in literacy scores for $16-25$ year olds $1994-2008$

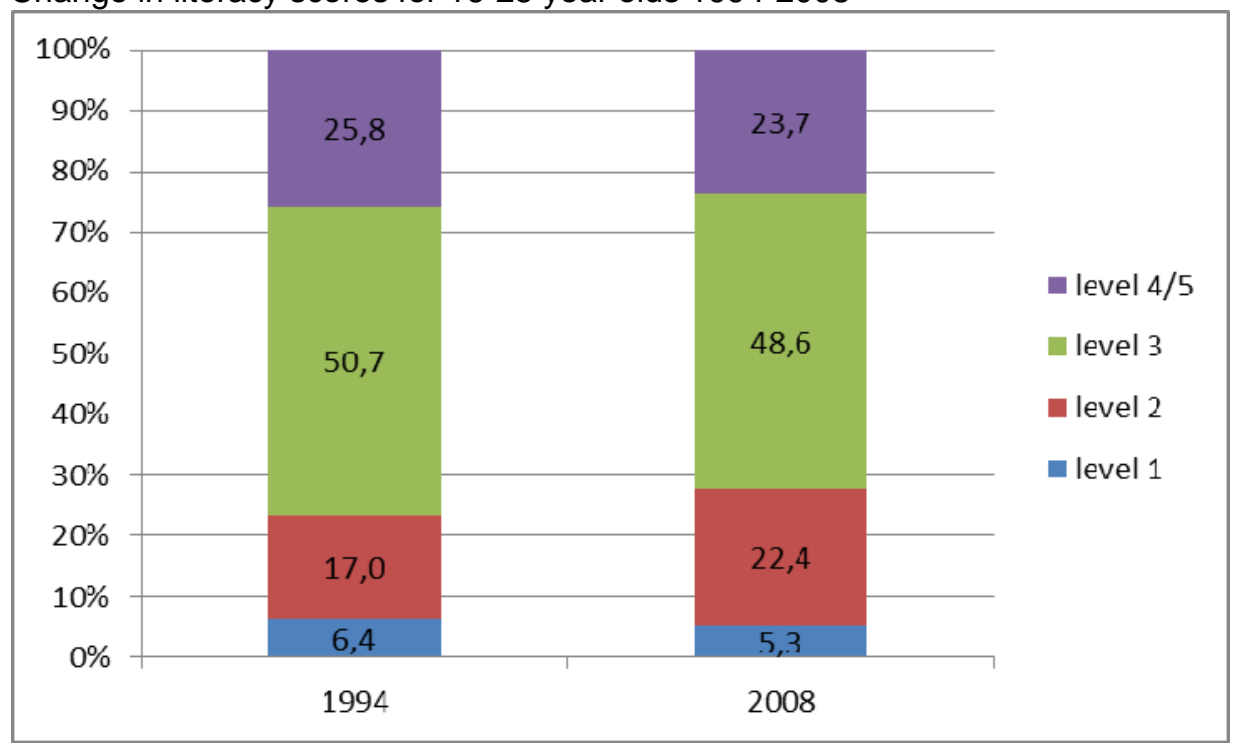

Source: IALS and ALL, own computations

This negative trend is also visible when we compare the recent results for the Netherlands from the ALL survey (held in 2008) with the comparable results from the earlier IALS survey (held in 1994). Between 1994 and 2008 the average score on document literacy for the total adult population decreased slightly, from 286.9 to 284.1. But the really striking thing is that this shift was much stronger for the younger age group of 16-25 year olds. The percentage of young people in the lowest literacy levels (levels 1 and 2) rose from $23.4 \%$ in 1994 to $27.7 \%$ in 2008 (see Figure 6).

$21^{\text {st }}$ century skills

All the results above relate to the more traditional basic skills: literacy, numeracy and science. But how does the Netherlands perform in other areas like the $21^{\text {st }}$ century skills? In general the assessments in these areas are scarcer or still 'under construction'. For problem-solving, the ALL data show that the Netherlands ranks highest of all eight participating countries. This domain (problem solving in technology-rich environments) is now being further developed in PIAAC, and we will have to wait for the results of that survey (to be conducted in 2012) to see whether the Netherlands can keep this high rank when more countries are involved. 
In the area of civic competences the results are less positive. Based on the International Civic and Citizenship Education Study (ICCS), Schultz et al. (2010) conclude that only one out of four Dutch students has a good understanding of what active citizenship implies. This is quite low compared to e.g. Finland and Denmark where more than half of the students has a good understanding. Around $15 \%$ of the Dutch students lack the necessary knowledge and skills to function well as active citizens and this percentage is higher than in most European countries.

Up to now no internationally comparable surveys have been conducted that assess ICT literacy. The IEA has planned a survey in this area to be carried out in 2013 (the International Computer and Information Literacy Study ICILS). Nevertheless there is some information available for the Netherlands. Van Deursen (2010) has looked at the level of internet skills for a representative sample of the Dutch adult population (18-80 year-olds). He shows that young people are better than older people in terms of medium-related internet skills (the operational and formal skills needed to use the internet) but do not perform better in terms of content-related skills, that is the skills needed to find and evaluate information and to strategically use it for their own purposes. The survey casts some doubt on the generally held belief that young people are fully equipped with the necessary ICT skills and that there is no need to develop this further in education. This may be true for medium-related ICT skills but does not necessarily hold for content-related ICT skills.

It has proven much more difficult to develop international assessments in the softer $21^{\text {st }}$ century skills like creativity, critical thinking, learning to learn, teamwork skills, communication skills, planning skills etc. (Murray, 2005). The evidence here is largely based on self-assessments which are more prone to cultural bias (Allen and Van der Velden, 2005) and therefore more difficult to compare across countries or subgroups. However they can still be useful for comparisons within well-defined groups over time, as there is no a-priori reason to believe that the unobserved factors driving these results change as well. A recent evaluation by Coenen, Meng and Van der Velden (2011) shows that in the academic tracks of Dutch secondary education (HAVO and VWO), self-regulation, collecting and processing new information and taking initiatives have clearly improved between 1998 and 2003. In other areas like teamwork, creativity and 
communication skills the results are more mixed, although most show a positive development over time.

\section{Educational attainment}

As described above, the Netherlands performs rather well when it comes to achievement as measured in large-scale assessments of the so-called basic skills, but how does it compare with other countries when we look at educational attainment? The percentage of 20-24 year-olds with at least upper secondary education was $76.2 \%$ in 2008 which is lower than the EU average of $78.5 \%$ and some $10-12 \%$ lower than the percentages in e.g. Finland and Sweden (Ministry of Education, Culture and Science, 2010). But this result is partly due to the differences between educational systems in the timing of programs at the upper secondary level. The percentage of 30-34 year-olds with a tertiary education degree is 9\%-points higher than the EU average: $40.2 \%$ versus $31.1 \%$. However, some countries score higher, like Denmark and Finland with respectively $46.3 \%$ and $45.7 \%$, and the Netherlands is still remote from the national target of $46 \%$ by 2020.

The percentage of early school-leavers among 18-24 year olds has decreased significantly from $15.5 \%$ in 2000 to $11.4 \%$ in 2008 . This overall percentage is still far remote from the objective of $8 \%$ that was set for 2010 . Still, the Netherlands performs better than the EU average, which is $14.9 \%$. And some of the countries that previously performed much better on this indicator (Denmark, Sweden) did not improve over time and are stuck at the same percentage of 11.5 and $11.1 \%$ respectively. This may indicate that further improvement is quite difficult to realize.

\section{Conclusion}

Summing up, the overall picture is quite good. The Netherlands ranks high in the assessment of basic skills and has been quite successful in decreasing the percentage of early school-leavers. There are also indications that a number of the so-called $21^{\text {st }}$ century skills have successfully been implemented in Dutch secondary education. 
An important area where improvements could be made is by a further increase in the enrollment in higher education. Regarding the basic skills a point of attention is the possible downward trend that has been observed. If this trend continues it could have major implications for the provision of relevant basic skills. Another area that deserves attention is the relatively low ranking of the Netherlands in the area of civics. As civics education is quite differently organized in different countries, it may be too soon to draw firm conclusions, but at least we need to give it some thought. Furthermore, there are indications that young people do not possess the content-related ICT skills needed to successfully use the possibilities that internet offers them. Finally, more research is needed that can shed light on how we are doing in terms of other $21^{\text {st }}$ century skills. We can also note that, for fairly obvious reasons, there is little internationally comparable data on how the Netherlands performs in terms of specific skills.

\section{$5 \quad$ Measurement and evaluation: what can we learn?}

When discussing measurement and evaluation we need to be clear on what we are trying to measure, how we expect to measure it and what purpose the information is expected to play in guiding educational policy and practice. We can draw a distinction between on one hand broad sectoral, national and international surveys for purposes of benchmarking and monitoring of skill levels in the broader population, and on the other hand assessment of learning outcomes of individuals, classes, departments etc. within education institutions for purposes of evaluating and directly influencing learning outcomes.

Large-scale assessments

The so-called $21^{\text {st }}$ century skills have so far only been integrated into large-scale assessment surveys to a limited extent, mainly because of a lack of validated methods that can be used to measure them. As a result, surveys such as PISA, TIMMS, CIVED, ICCS, IALS, ALL and PIAAC have focused mainly on basic skills in the domains of literacy, numeracy, math, science and civic engagement. Recent developments in ICT use for assessments (simulations, adaptive testing etc.) have greatly improved the possibilities to develop tests that are more authentic and complex. The IEA is currently developing a new instrument for assessing the level of ICT skills and the PIAAC survey 
has developed a test for broader ICT-problem-solving skills (which are more focused on people's abilities to use technologies purposefully than on their more narrowly defined ICT-skills). Apart from these developments, there has been little attention in large-scale assessment surveys for the broader area of $21^{\text {st }}$ century skills. Attempts to broaden the scope of PISA to include so-called cross-curricular competencies (OECD 2004) have not been met with broad acceptance, partly because of the difficulties involved in developing reliable and broadly accepted indicators that are comparable across relevant (sub)populations. The heavy reliance on self-assessment means that the measures obtained are not convincingly different from those available in various broader social surveys.

There has been considerable discussion as to the policy relevance of skill measures obtained from large scale assessment surveys in the light of the rather narrow focus on a few basic skills. Many have argued for the desirability of extending large-scale assessments to include such things as so-called non-cognitive skills like social and communication skills. The proponents of such measures argue that such skills are as relevant or perhaps even more relevant for economic and social outcomes of education. These scholars worry that the absence of valid and internationally comparable measures of such skills will result in biased estimates of the effects of the skills that are measured, and in erroneous policy conclusions that could lead to a diversion of resources in favour of measurable skills and to the detriment of skills that are more difficult to measure.

The proponents of large scale surveys in their current form are quick to point out that the skill measures are strongly related to economic and social outcomes, both at an individual level and at the level of countries as a whole. Based on an analysis of the observed relation between test scores and economic growth, Hanushek and Woessman (2011) argue that a net improvement in PISA scores by $1 / 4$ of a standard deviation would have increased economic growth in OECD countries by some $288 \%$, or US\$ 123 trillion, by 2090 . They show that the skill measures completely account for the projected effect of increased educational attainment on economic growth in OECD countries.

Regardless of the outcome of this discussion, few scholars deny that a regular assessment of basic skills in surveys such as PISA is valuable. There is however strong disagreement as to what role such assessments should have in guiding educational policy and practice. At one extreme there are those who advocate directly confronting 
educational institutions with the results of such assessments and challenging them to do better (e.g. Ritzen, 2011). In the Netherlands this is already done to some extent through the actions of the education inspectorate in using CITO-scores for assessing schools (although not based on large-scale assessments, the publication of performance indicators in the higher education choice guide has a similar effect). Others point to the problems inherent in linking such assessment too tightly to policy and practice, arguing that in order for this to be effective, both the content of the assessment and the modes of assessment need to be carefully designed in order to ensure a positive impact on education. Beller (2011) argues that effective assessments need to be complete, authentic and fully integrated into the learning process. Large scale assessments are currently none of these things, and it is doubtful whether they can (or even should) ever be designed in such a way. Attempting to use such data directly to guide educational policy and practice would result in a misalignment between teaching and learning, content and performance standards, and assessment, and are likely to result in an unwanted diversion of resources, "teaching to the test" and the like. More in general, the risk arises that education comes to be seen by students, teachers, schools or policymakers too much as a contest that needs to be won (who is at the top of the ranking list?), if necessary using calculating strategies, and too little as a means to gain a better understanding of the strong and weak points of their education.

The strength of broad surveys and their importance for educational policy and practices lies in the comparability of the measures obtained over whole populations or subgroups thereof. Even when only applied to a subset of the full range of skills needed for work and life in general, such information is highly informative, as long as the subset is shown to be sufficiently relevant to key outcomes (Hanushek and Woessmann, 2011). Differences between countries and subpopulations within countries are useful for identifying populations at risk and assessing progress or decline over time.

\section{Assessment within schools}

In contrast to large-scale assessments, assessment of individual learning processes and outcomes in schools are not only focused on basic skills, but also on $21^{\text {st }}$ century skills and domain specific skills, with an aim to monitor and where necessary intervene in the learning process. As mentioned above, it is important to achieve a good alignment 
between the content and performance standards strived for, the teaching and learning methods applied, and the methods of assessment used. Against this background, Geller (2011) points to the need to strike the right balance between formative and summative assessments. Summative assessment aims to summarize the learning that has taken place at a given point on time. The outcome of summative assessment can be useful for diagnosing problems, identifying weaknesses etc., but plays as such no role in the learning process. By contrast, formative assessment is a bidirectional process between the teacher and the student which itself plays a role in facilitating learning to enhance, recognize and respond to the learning (see e.g. Black and Wiliam, 1998; Cowie and Bell, 1999). Wiliam (2010) identifies five key strategies for using assessment to improve the quality of instruction:

1. clarifying what students are expected to learn and what the criteria for successful learning are

2. facilitating the development of activities that can make clear to what extent learning is actually taking place

3. providing feedback that students can use to help them move forward

4. enabling ways for students to learn from each other

5. encouraging students to take responsibility for their own learning.

New developments in ICT appear to have enormous implications for the possibilities for formative assessment. Beller (2011) points to developments that can improve the efficiency and quality of existing assessment practices in education (e.g. automated test instrument development, computer delivery of tests, automated scoring of complex items) as well as developments that could potentially expand the scope of assessment into new domains (e.g. simulated assessment tasks, intelligent tutoring systems and virtual reality systems). She points out that new technologies can also enable far richer, more authentic tasks to be developed than can be used to probe out precisely the kinds of things referred to under the heading $21^{\text {st }}$ century skills, such as integrated knowledge, critical thinking and problem solving. At the same time, she also recognizes that there are major hurdles to be overcome before this huge potential can be utilized. For a start, it is far from clear that schools are currently equipped - pedagogically, technologically, logistically and socially - to implement technologies such as described above into the teaching, learning and assessment processes. If these issues cannot be adequately resolved, the risk exists that (partial) implementation of systems into education may 
impose an unwanted burden on schools without this resulting in clear benefits, at least in the short term. Particularly in a time when educational budgets are coming under increasing pressure this is a serious issue.

New technologies have also radically changed the world of large scale national and international assessments, and this has led some to suggest that such large scale assessments can be more or less fully integrated into learning processes so as to play a direct role in both summative and formative assessments. The more continuous approach to assessment applied by CITO in Dutch primary education on the basis of the a continuous learning approach (Referentiekader Doorgaande Leerlijnen) is an example of such an approach, allowing timely diagnosis of problem areas and where necessary corrective interventions. Another example of such an approach is the so-called "cognitively-based assessment of, for, and as learning" approach (CBAL) (see O'Reilly and Sheenan 2008), which aims to spread out assessments over the whole school year and incorporate formative elements into the assessment process as an aid to teachers. The ambition of the CBAL consortium is to use new technologies to fully integrate largescale assessments into the learning process. It is too early to judge to what extent such initiatives can realistically achieve all of their aims. If nothing else, analysis of the results of such initiatives can yield valuable insights into the relation between the outcomes of more conventional large scale assessment surveys and the more detailed and tailored learning outcomes strived for by schools.

\section{Conclusion}

Measuring and evaluation of the achievement of students is key for any improvement of the skills of the population. Supported by new developments in ICT, our ability to measure a wide variety of skills in a valid, comparable and authentic manner has improved dramatically in recent years. There is however still much to be done, particularly in the areas of softer skills, and possibly also in developing comparable measures of specific skills. We have to be careful how we apply the information we do obtain. Although a certain degree of competition in education can be healthy, we have to avoid a situation where education is viewed by those involved as a contest in which the aim is to score well on assessments rather than to promote the learning process. Results of assessments can be useful indicators of where we stand in terms of skills, but 
only if linked in an authentic way to educational goals does it make sense to integrate these into the learning process or directly link them to educational policy.

\section{$6 \quad$ What are the challenges that education is facing?}

If we look at the many changes in today's world, the implications these changes have for the skill needs of the population and the central role of education and training in supplying these skills, it is clear that the task for education and educational professionals is unprecedented. The challenges that education is facing are many, but we would argue that the greatest challenge, which has enormous implications not only in itself but for the chances of meeting the other challenges, is the expansion of ICT use in schools. Within a very few years a tsunami of ICT is set to wash over education, and our education system is at present not fully equipped to deal with this. Young people are more ICTsavvy than their teachers, and ICT will enter the classroom whether we want it to or not. The problem is that the medium-related skills of young people are not well matched by content-related skills, and that teachers are currently not well placed to guide them in learning the latter type of skills. Nor are teachers currently sufficiently ICT-literate to make use of the enormous potential offered by new technology in terms of interactive and iterative learning and assessment, open source content and the like.

If the successful implementation of ICT into education was the only challenge, there would be some reason for optimism. With the exception of the fact that our teachers are as yet underprepared, in other respects Dutch education is already rather advanced in terms of the implementation of ICT infrastructure. There are however many other challenges. Some of these challenges result from changes in the input in education such as the student population, budgets or the teacher population. Other challenges result from required changes in the process of education, for example the introduction of innovative learning environments, or the timing and organisation of the education process. And of course some challenges are directly related to changes in the required output of education that is changes in the skills that need to be taught. Below we list some of the most salient challenges. 


\title{
6.1 Challenges related to the input
}

\author{
How to deal with individual differences?
}

As indicated in Section 2, student populations in schools have become more diverse. They are becoming more mixed in terms of ethnic, socio-economic and religious composition, and also in terms of marital status of parents, with a profound increase in the number of students from single parent families. Primary and secondary education has seen an increase in the number of students who have some form of learning disability. In higher education we see an increase in the number of international students, mature-age students, part-time students and students from lower social strata. Moreover, the sheer increase in the participation in higher education as well as in the higher tracks of secondary education also implies that there is more variation in talents and abilities.

An interesting phenomenon in this context relates to the rising gender differences in favour of women. In most western countries women have overtaken the dominant position of men. They now form the majority of students in higher education, they perform better on language tests, and in some countries they even do better on math tests. By contrast, men often have a more problematic school career: they are more likely to drop out of high school, get referred to special education, and repeat grades.

There is still some dispute about the general desirability of diversity (for a brief overview see Dronkers, 2010), but there is consensus that diversity at least increases the workload of teachers and the complexity of their task. Diversity decreases the efficiency of classroom instruction and increases the need for individual instruction to students that lag behind or have different educational needs. This may have a negative effect on the average performance of students. It is clear that the increase in diversity calls for more differentiation and more tailor-made solutions. The 'one size fits all' approach that is still very dominant in education will need to be abandoned. 
How to deal with all the challenges with fewer resources?

Budgets for education in all western countries are increasingly under pressure. In 2006 the average spending in the Netherlands on education was $5.6 \%$ of GDP, which is close to the EU (5.5\%) and OECD (5.8\%) average. We are now facing an era in which budgets are being frozen or decreased. The financial crisis forces governments to make drastic cutbacks in their expenditures. Even when total expenditures for education have not decreased, the mean expenditure per student has. This is felt most strongly in higher education (OECD, 2008). The falling expenditures per student in higher education are likely to lead to a reopening of discussions related to access to education, the role of education in reducing social inequalities, and such. In addition, challenges will arise related to the possible social exclusion of those groups in society who for whatever reason do not progress to higher education.

These problems are exacerbated by major demographic changes in the labour market. Current forecasts show that education and health care are the two sectors most likely to be confronted with shortages in the supply of personnel in the near future (ROA, 2009).

This is made worse by the skewed age distribution of the Dutch teacher population. 33\% of teachers in primary education and $44 \%$ of teachers in secondary education are aged 50 years or older. This compares negatively with the EU average of $28 \%$ and $36 \%$ respectively. Like all older people, older teachers are prone to processes of cognitive decline. Consequently, their ability to process new information, to adapt to changes in the environment, and so on is likely to decrease. In combination, these changes mean that Dutch education has to successfully implement curriculum reforms, introduce ICT tools into education and meet all the the other challenges it is facing with increasingly strained budgets and a shortage of teachers, particularly those in the younger age range who are likely to best be equipped to deal with the changes. 


\subsection{Challenges related to the process}

\section{How to deal with a need for more flexibility?}

It is clear that the above-mentioned increasing diversity of the student population has implications for the organisation of the educational process, mainly in terms of differentiation. This by itself induces a need for more flexibility. The need for flexibility is further increased by the role that VET and higher education are expected to play in lifelong learning.

Lifelong learning implies that VET and higher education will be faced with an increased demand for short, tailor-made courses for adults. In order to keep pace with changes in the work environment, adults will increasingly return to education or forms of non-formal training, to update their current skills, to increase their level of skills or to change their skills set completely. The current educational institutions in VET and higher education are hardly prepared for this new type of student (Denktank Leren en Werken, 2009). These institutions and the programs they offer are organised to function as initial education, with largely homogeneous groups of students in terms of educational needs who all start at the same time at the beginning of an academic year. If these institutions are to play a significant role in lifelong learning, they will need to completely change their orientation and organisation of the educational process. This will include the formal assessment and evaluation of previous learning experiences (EVC) in order to assess the current skills of the adults entering the educational programs. As both the entry skills of adults as well as the desired output level of their skills will differ significantly, individual tailor-made trajectories need to be designed. And these individual trajectories need to be offered in a way that is highly flexible in terms of time (starting dates and end dates, contact hours in evenings or weekends) and place (e-learning, etc).

How to successfully implement innovative learning environments?

Over the past two decades there have been many advocates to promote the use of innovative methods to develop the $21^{\text {st }}$ century skills and indeed these methods have been widely introduced in education. In the Netherlands most - if not all - of the programs in upper secondary and tertiary education use some form of student-centred 
method like self-regulated learning, problem-based learning or project-based learning, and the goals of education are defined in competencies rather than skills. The OECD Centre for Educational Research and Innovation (CERI) has made a valuable contribution to this discussion with the publication of the report 'The Nature of Learning' (OECD, 2010a), in which leading scholars advocate the development of innovative learning environments such as inquiry based learning, collaborative learning and other student-centred modes of teaching.

There is ample evidence that these innovative learning environments indeed foster relevant $21^{\text {st }}$ century skills like communication, cooperation and problem-solving skills. Nevertheless there are some caveats. That is to say, innovative modes of teaching and learning can be highly effective, but only under specifically proscribed circumstances. Failing to meet these conditions may render these innovative methods less efficient or even ineffective. To give a few examples:

- There is probably little doubt that cooperative learning has a positive effect on cooperation skills, but the effect on cognitive achievement is less straightforward. Group dynamics may lead to a less than desirable learning environment and there is the constant danger of free riding. Slavin (2010) points out that cooperative learning only yields positive results on achievement outcomes when two conditions are present: clearly defined group goals and individual accountability. When these conditions are not met it is unlikely that cooperative learning will be effective.

- Self-regulated learning is generally seen as an important way to develop metacognitive skills and to increase intrinsic motivation. It is therefore one of the key constituent elements of many innovative learning environments (e.g. the Dutch educational reform in secondary education, the "Studiehuis"). Recent insights from the neurosciences however shed some doubt as to whether self-regulated learning is always possible (Jolles, 2007). It turns out that the adolescent's brain is not yet ripe for engaging in the long-term planning that is necessary for effective self-regulation. This applies more to boys than to girls, which is probably one of the reasons why boys have profited less from the introduction of selfregulated learning in the "Studiehuis", than girls, as was shown by a recent evaluation by Coenen, Meng and Van der Velden (2011). It is crucial to take 
these and similar insights into account, in order to specify the conditions under which self-regulated learning is likely to be effective.

- There is strong evidence that inquiry-based learning approaches such as project-based and problem-based learning develop academic skills. Students learn more deeply when they can apply classroom-based knowledge to real world problems, all the while nurturing $21^{\text {st }}$ century skills like communication, cooperation and creativity. However it is less evident that this is always the most effective way to develop specific skills. To develop a body of knowledge in a given domain, students need structure. This structure enables them to see how new information fits within their existing frame of reference. In a traditional classroom setting this structure is usually provided by the teacher who acts as an expert, or by the classical textbook. This structure helps students to build a good overview of the whole body of knowledge to be learnt. Meng (2006) has shown that in a situation where the role of teachers is limited to supervising the process rather than serving as an important source of information, the development of domain-specific skills lags behind.

- And finally, an excessive focus on innovative methods may easily obscure the fact that effective skills acquisition also requires practice, repetition and routine. Although we take this for granted in the case of skill acquisition in sports or music, it seems that for other skill domains this has become something oldfashioned and out-of-date. But there is no reason to assume that acquiring expertise in whatever domain can do without some form of practice and repetition.

The list can easily be expanded. The main message is that the success of innovative learning methods is crucially dependent on the conditions under which they are implemented. The knowledge about which conditions are crucial is unfortunately less well developed and also less widespread than the methods themselves. Many of the technologies listed above in relation to assessment (Beller, 2011) are potentially relevant to the implementation of innovative learning environments, and can, if used appropriately, help solve some of the problems related to their implementation. Once again however, this requires a teaching staff who know how to deal with the technologies in question. 


\subsection{Challenges related to the required output}

Which skills should be developed in education and when should this take place?

Although most scholars would agree that education is an appropriate place to develop basic skills and many of the $21^{\text {st }}$ century skills as well, there is a major issue of timing and organization into the curriculum. Education is faced with demands in many areas, ranging from traditional disciplines like language, math, science and vocational subjects, new domains like civics and health, as well as all the $21^{\text {st }}$ century skills, and meeting these demands takes time. By definition however, time is limited. Even if we could agree that it is possible to increase the workload for students in education, there is a natural limit to the number of hours that can be spent in a school day, a school week or a school year. This makes time in education precious, and we need to think very carefully how that time should be apportioned. In deciding the amount of time that should be spent on each of the different skill domains we need to ask ourselves the following questions:

- Is education the most efficient environment to develop these skills?

- Are these skills more important to develop than other skills that could be developed in education?

- At what age can these skills best be developed?

- Is the development of a certain skill a prerequisite for the development of other relevant skills?

- What would happen if we did not develop these skills in education?

In a number of cases the answers to these questions are pretty straightforward. In the case of basic skills such as literacy and numeracy, there is abundant evidence that children are biologically predisposed to learn these skills, and that education is the appropriate place for a large part of this learning to take place. As Hinton and Fischer (2010) point out, the brain is biologically predisposed to acquire language and work with numbers, but learning formal written language and math is a painstaking cumulative process that takes time, as formal linguistic and mathematical abilities are overlaid on top of the brain's natural capacities in these areas. Research has shown that in both cases there are clearly different ways in which this overlaying can take place, some more effective than others, which underscores the desirability of allowing this learning to 
take place in a controlled learning environment, i.e. in formal education. The efficiency of the learning process in other skill domains will be greatly enhanced once a basic level in these domains is reached, which is why teaching these skills needs to be done at a very young age.

In other cases the situation is less clear. Civics, health literacy and financial literacy are all considered important skills, but it is not obvious that education is the most efficient environment to develop these skills. And even if this is the case, allocating time to these subjects will presumably have to be at the expense of science, math, language, or some other subject that is currently taught, which means that we have to weigh the gains in one subject against possible losses in another. In the case of typical $21^{\text {st }}$ century skills, the role of education is even less obvious. As such there is no reason to doubt that skills like cooperation, communication and ICT literacy can be developed in education. The main question is whether this constitutes an efficient usage of the scarce resources available to schools. If this was a matter of devoting explicit space in curricula for developing such skills, the answer may well be no. With the possible exception of ICT skills, it is far from obvious what lessons explicitly designed to develop these skills would look like. However, the development of $21^{\text {st }}$ century skills in education is primarily a matter of the form, rather than the content of education. This insight has formed the primary motivation behind the introduction of innovative modes of teaching and learning. The question is then not so much whether cooperative, student- and inquiry-based learning fosters communication, cooperation and problem-solving skills, but at what time in the educational career they can best be introduced and in what manner (see the discussion above on the circumstances under which these methods are effective).

In short, policymakers and educational practitioners need to think very hard about their priorities, not only in terms of what is to be taught in education, but in which form, at what time, and in which order.

Developing the top, the middle or the bottom?

One of the biggest challenges facing educational systems today is that they are torn between two major objectives that to some extent at least are in conflict with each other. On one hand there is enormous pressure to make resources available to develop talent 
at the top of the skills continuum. As indicated earlier the Dutch educational system is less effective in developing top talent and is lagging behind when it comes to the upper end (top 5\%) of the distribution (Minne et al., 2007). In the past decade many schools and institutes in secondary and tertiary education have developed special programs (bilingual programs, honours programs etc.) for this group, but it is still unclear whether this is enough to develop real top talent. One might assume that this has negative effects on the innovative capacity of the Dutch economy, but in fact the empirical support for the existence of such effects is quite thin (Minne et al., 2007). In its review of the Dutch higher education system, the Commission Veerman (2010) adopted quite a different position. In their view the Netherlands has relatively many top researchers, as indicated by the number of patents, but has to date been not very successful in translating this into commercially viable activities. If this is true, developing top talent may not be the best way to proceed, and it would probably be better to invest in the transfer of knowledge between education and (especially medium and small) enterprises.

The second major objective is that schools are expected to address the serious problems facing those at risk of leaving school with little or nothing in the way of useable skills. Here we might face a problem of diminishing returns. As indicated earlier, the Netherlands has done quite well in terms of decreasing the number of early schoolleavers, and although there are indications that some further improvements can be made (Allen and Meng, 2010), it is clear that we have passed the phase of "picking low hanging fruit'.

The attention given to the two groups at the extremes of the skills distribution - to be clear, we are talking about the top 5\% and the bottom 10\% - could easily obscure the fact that education systems are also expected to provide high quality education for the much larger group of students who lack the potential to become geniuses, but who are nonetheless sufficiently gifted to do well at school and make a valuable contribution to the economy and society. Numerically it is this group who make up the bulk of the work force, so it is crucial that they receive adequate schooling. Moreover this is the group most likely to be faced with the consequences of the polarization of the job structure, leading to an increased need for an upgrading of their skills. 
If infinite resources were available, it would be easy to address the needs of all three groups mentioned above. However this is not the case, and educational policy will need to make clear how to divide its resources over these three groups in the years to follow. Although it is important to continue paying attention to the top and bottom groups, for these we have perhaps reached the point of diminishing returns, so it is unlikely that extra investments in these groups will pay large dividends. By contrast, general improvements in education along the lines sketched above should pay large dividends when focused on the larger middle skill range group which makes up some $85 \%$ of the youth cohort.

\section{How to deal with the narrowly gifted?}

One key feature of the new skill requirements is that different skill domains are becoming increasingly interlinked. To give an example: technicians and engineers do not only need to be experts in their own professional domain, but are also required to possess general skills such as an ability to communicate well or a strong customer orientation. As well, tasks in modern math curricula do not only require traditional math skills, but often also require a rather high level of reading skills in order to understand the task at hand. In short, it seems as if everybody needs to be a "Jack of all trades", and many of the $21^{\text {st }}$ century skills are assumed to be essential for everybody.

This may pose a problem for those who have outstanding talents within a more narrow range of skills. People differ in their innate abilities and interests, and it is unlikely that everybody will be able to achieve the same minimum level for every skill. Education programs seem to offer little room for these more narrowly gifted students. Students in vocational education who may be excellent craftsmen are increasingly forced to follow courses in such things as language, math or civics, as well as to develop good communication and teamwork skills and the like. This may lead to motivational problems and even dropout for these often exceptionally talented students. Similarly, students in general secondary education who are narrowly gifted in science or humanities are faced with obstacles in their school career because they are not only being assessed in domains in which they excel but also in domains where their talents are poor. 
The fact that the labour market requires most people to be competent in all these areas does not mean that there is no room for a small number of highly specialised people. On the contrary, in many areas work has become so complex that it is only comprehensible to select groups of specialists. We cannot afford to lose the talents of these narrowly gifted students and it is a task for education to allow these students to optimally develop their talents in the areas in which they excel.

\section{$7 \quad$ What does education need to do?}

The changes in the knowledge economy require more than just the development of $21^{\text {st }}$ century skills but also require further improvements of the level of basic skills like literacy and numeracy. Moreover the upgrading of many jobs requires an increase of the participation rates in higher education. This implies that many actions that are aimed to improve the general quality of education coincide well with the requirements that were listed above. This holds for example for the importance of early intervention programs to ensure that young, low-skilled children who enter primary education possess the skills they need to keep up with their more gifted peers and to ensure the efficiency of subsequent learning processes (prevention is the best cure). In this section we will not dwell on these more general actions, but concentrate on actions that are specifically related to the challenges listed above.

\subsection{Actions related to the input}

\section{Professionalization of the teachers}

Research shows that $75 \%$ of teachers in primary and secondary education currently use computers in their classes (Kennisnet, 2010). This percentage increases by 2-3\% annually so that the gap will be closed in 10 years time. Although most teachers have the medium-related skills to use the computer in their class, the proportion of teachers who is fully aware of the didactic possibilities of ICT is rather low. And more than $40 \%$ of the teachers does not feel confident enough about their ICT skills to actually teach ICT skills (Kennisnet, 2010). It will therefore not come as a surprise that the use of modern technology in education is far less developed than is desirable. Most of the programs 
being used relate to standard programs like e-mail, internet or text editors. The use of curriculum specific ICT tools is less well developed.

A successful implementation of ICT in education demands more than just an investment in hardware (Zucker and Light, 2009). To change the educational practice, a balance needs to be struck between vision, expertise, digital learning materials and ICT infrastructure and the best strategy is to start with the human factors: vision and expertise (Kennisnet, 2010). It is vital that educational managers and professionals develop a shared vision on what they want to achieve and how to develop their expertise. To develop the ICT skills is not just a question of learning some technical skills. It takes a long time before teachers have developed the didactic skills that are necessary to optimally use ICT tools in their curriculum (Kennisnet, 2010). As with many other skills this can best be developed in a combination of non-formal and informal learning.

The non-formal learning of ICT skills could be a (mandatory) part of their overall professionalization. Schools are expected to spend some $10 \%$ of their budget on training but little is regulated on how this is done. In this respect it is strange to note that the current Act Occupations in Education ('Wet BIO') does not have any reference to the level of ICT skills that teachers need to have, despite the fact that for other areas these skills levels are described ("Vakbekwaamheidseisen"). Having a good description on what is expected of teachers in this area is an important step forward.

In other professional sectors like health care we can see that professional associations play a major role in developing the standards and organizing non-formal training to keep the skills of the professionals up-to-date. Unfortunately these professional associations in education are weakly developed in the Netherlands. It would be good to stimulate discipline-related networks of teachers to take a role in the development of professional standards, course material, open content, dissemination of good practice and training of professionals. 


\subsection{Actions related to the process}

Develop and disseminate systematic knowledge about the conditions under which innovative learning methods are successful.

The success of innovative learning methods is crucially dependent on the conditions under which they are implemented. Unfortunately systematic knowledge in this area is still lacking. It is important to build up a coherent knowledge base about the effectiveness of innovative learning methods and to ensure that this knowledge will be disseminated to educational professionals. Current research programs by the Dutch Scientific Council NWO-PROO and the Top Institute for Evidence Based Education Research TIER have already started to explore the conditions under which innovative learning method are effective. It is important that this knowledge base will be systematically further developed. Moreover it is vital that this information is disseminated to the educational professionals, not only in the initial training of teachers but also to those who are already working in the field. It is important to develop an authoritative standard that teachers can follow when using these methods.

Integrate the use of ICT skills in core curricula

Very often the fact that students usually have better ICT skills than their teachers is taken as an argument not to teach ICT skills in education. This is probably true for the more technical ICT skills, the ones that Van Dijk (2005) defines as operational ICT skills and formal ICT information skills. OECD (2010b) shows that in countries like the Netherlands, England, Austria and the Nordic countries 95\% or more of the 15-year-olds use internet on a daily basis. We would argue that such skills per se are in general not efficiently developed in education: the technology changes too quickly and in any case young people develop the relevant skills largely in private life. There is no need to make the application of innovative technology an explicit goal, but rather barriers to using such technologies for learning and inquiry should be removed as far as possible, for example by organizing assignments in such a way that it is efficient for students to use the latest technology. Under such conditions, the fastest students will need no further prompting to make use of the technologies they are all too familiar with, meaning that the students themselves will introduce the technology into the classroom. By incorporating this into 
cooperative, inquiry-based methods under the conditions described above, the slower students will develop ICT literacy by following the example of their faster peers.

However the situation may be different for the more content related part of ICT skills, the substantial ICT information skills and strategic ICT skills. Van Deursen (2010) shows in an experiment that the overall level of content-related internet skills of young people is much lower than their medium-related skills, and that young people do not perform better than older people on such skills. This part of ICT literacy consists of generic skills such as developing information-processing skills, logical thinking, deductive reasoning and the like. These skills are already part of the curriculum in education, but their significance has increased even more in a technology-rich environment. The vast amount of information available on the internet has given rise to problems related to locating and evaluating information for quality and credibility. Students need to learn how to evaluate and appraise the information they can find on the internet and developing these content-related internet skills should be part of the curriculum.

Promote the use of open content and show examples of best practice

One of the important implications of the ICT development in education is that it changes the role of the teacher as an autonomous professional who is solely responsible for developing the curriculum, teaching and assessment. Through the use of modern technology, communities of practitioners emerge who jointly develop curricula and make them available through open resources. Teachers can choose from materials already developed elsewhere. Students can follow lectures by the best teachers in the world. This will probably have a positive effect on the quality of teaching, and decrease the variation in teaching quality as individual differences between teachers become less important. Education can and must benefit from the ICT revolution, making use of the possibilities created by for example open content, mobile technologies and innovative interfacing technologies. Education should embrace such ICT innovations and use them to improve the way education is organized. The best way to promote this practice is by using existing professional networks and by making it part of the training of teachers (see above). 
The success of each innovative learning method is critically dependent on the presence of well-designed assessments. It is clear that not only the curriculum but also the way we assess students drives the learning process (Van der Vleuten, 1996). However, the kinds of skills that are needed to pass an exam are often quite different from the skills we aim to develop. There is little value in using multiple-choice exams that merely test the short-term memory capacity of students when the actual aim is to develop academic skills. It is therefore important to align the way we assess students with the objectives of the curriculum, for example by using some form of authentic assessment.

Related to this, in many cases exams are used as a purely summative evaluation of whether the student has passed or failed the course. Wiliam (2010) makes a strong case for the role of formative assessment, in which the results are used to give feedback to students about their progress, and to diagnose any remaining tasks that have not been mastered yet. Students often need help understanding the problem they are aiming to solve, and in developing their strategy for solving that problem, they crucially rely on effective feedback to ensure that they learn from their mistakes. They will learn little when the only feedback is that they passed or failed the exam.

\section{More flexibility in the exams}

One way of dealing with the problem of the narrowly gifted is to allow exams to be taken at different levels, depending on the subject taken. As in the international baccalaureate, students should be allowed to take an exam in some subjects at say VWO level and in other subjects at HAVO level or even below (see also Onderwijsraad, 2007). As is the case now, courses in tertiary education can formulate specific requirements about the subject as well as the level of the exam that needs to be taken in order to enter the program. This flexibility would solve many of the inherent problems of the early tracking system and would allow for an optimal development of talent. 


\subsection{Actions related to the output}

Develop systematic knowledge about what should be learned and when.

Education is facing many and sometimes conflicting demands. But instruction time in education is by definition limited and this means that there will trade-offs. These tradeoffs are complicated. More time spent on one skill domain will often be at the cost of skill acquisition in another domain. But improving skills in one domain (e.g. literacy) may also improve the efficiency of later skills acquisition in another domain (e.g. history). Another issue relates to the timing of skills acquisition. Some domains are more effectively developed in early childhood, while others are more effectively developed during adolescence. And finally, we need to know how the skills that are acquired in education affect relevant economic and social outcomes.

Educational policy needs to make complex decisions about what needs to be taught in education, when this learning should take place and how the learning process should be organised. The how question is often a prime focus of teachers and educational researchers and in recent years we have seen a strong movement towards evidencebased innovations (but see our earlier remark on the lack of knowledge on the conditions under which these innovations are successful). However regarding the what and when questions, we still lack a thorough understanding of the educational production process. The 'technology of skill formation' (Cunha and Heckman, 2007) is still to a large extent a black box. It is important to systematically develop our understanding in this area by developing a simulation model of the educational production process and its effects on social and economic outcomes. Such a model can serve as a basis to make educational policy on what and when questions more evidence-based.

Remove obstacles for the enrolment in higher education

The objective of Dutch educational policy is to further increase enrolment in higher education. This is also necessary because the polarisation of the job structure forces more and more medium-skilled workers to upgrade their skills to a tertiary level. However there are three bottlenecks in the Dutch educational system which may hamper further increases in the enrolment in higher education. 
One is the narrow basis for recruitment of students from the academic tracks in secondary education: HAVO and VWO. The largest share of enrolment in higher education comes from these two academic tracks. Although these two tracks show a steady increase compared to the lower tracks in secondary education, they still make up less than $50 \%$ of the students. Especially the share of HAVO is lagging behind compared to the distribution of teacher's advices and test results at the end of primary education (Borghans et al., 2008). In order to increase enrolment in higher education the basis in secondary education should be broadened, which means more enrolment in HAVO.

The second obstacle is the long route to higher education that is followed when students choose the vocational tracks. Compared to students from HAVO, it will take students from vocational tracks (VMBO) 3 years longer to proceed to higher vocational education (HBO). Given this long route it is surprising that so many students actually follow it successfully, and it is questionable whether this can be simply increased further. It is important to develop shorter routes to allow talented students in vocational education to proceed to higher education. More in general it would be good to develop honours programs in vocational tracks (VMBO, $\mathrm{MBO}$ and $\mathrm{HBO}$ ) to raise the reputation and attractiveness of these tracks.

The third bottleneck is the lack of differentiation in higher education, especially in HBO. Compared to other countries the share of short cycle courses (Associate degrees) is very low. It has been argued that the 4-year courses in MBO fulfil the same function as Associate Degrees in other countries, but a recent evaluation by Coenen and Van der Velden (forthcoming) shows that this is not the case. The lack of differentiation in HBO seriously hampers the further participation of students and adults with an MBO qualification. It is important to develop both the short cycle courses as well as the dual courses in tertiary education. This will make tertiary education more attractive for students from MBO who want to continue in education, but do not want to follow a 4-year program as well as for adults who want to upgrade their skills level. 


\section{Conclusions}

The main conclusions that can be derived from the analysis provided in this essay are listed below.

Important as the so-called $21^{\text {st }}$ century skills may be, educators should base their programs and education systems more on state of the art knowledge about the full range of skills needed in the world of the future, including basic skills and specific vocational skills. They need to base educational policy and practice on the best available information and learning models on how these different skills can best be developed, for which skills there exists a comparative advantage of developing them in initial education as opposed to other life domains or in post-initial education, at what developmental stage different skills can best be learned, what prior skill basis is required in order to effectively develop later skills and so on.

Within a very few years we can expect a tsunami of ICT to wash over education systems that are in many ways still ill-equipped to deal with the changes this will bring. It is important to realize that ICT will enter the class (to a large extent it already has) whether schools and teachers want it or not. In terms of the latest technology, young people are far more ICT-savvy than older people, and they will bring their versatile hand-held devices into the classroom and expect to use them. The challenge facing schools is not to teach children medium-related ICT skills, which are in most cases superior to those of their teachers. The challenge for schools is to ensure that ICT is used in a constructive rather than a disruptive manner. The ICT revolution may be a double-edged sword: on one hand it offers huge potential in terms of introducing innovations into education that would be unthinkable without such technology, while on the other hand the sheer complexity and volume of the changes threatens to inundate education, thereby largely undoing many of the potential advantages. The main potential advantages lie in the access to a much richer range of content through the internet, and in the availability of dramatically improved levels of interactivity in the learning process and in assessment. In the Dutch case the main bottleneck holding schools back from realizing such advantages may be the inadequacy of teacher training, particularly in the area of making teachers aware of the didactic possibilities of ICT in the classroom. Developing such skills is a time-consuming task, and is unlikely to be systematically achieved unless it is 
explicitly taken up as a (mandatory) part of their overall professionalization. This is especially important since teachers will need to bear the responsibility for ensuring that young people develop their content-related ICT-skills, which at present are lagging seriously behind their medium-related skills. In the absence of expert guidance, there is a real danger that students will mistake the huge volume of the information flow at their disposal for genuine insight.

Innovative learning environments have already been extensively implemented in Dutch education, but there is concern at the effectiveness of these methods if not administered appropriately. There is little doubt that such methods can be effective in fostering $21^{\text {st }}$ century skills in areas such as teamwork, communication and problem solving, but there is some concern that the conditions are not being met for these methods to be effective in developing basic skills, core subject knowledge and domain-specific skills. It is of key importance that the insights into these conditions for educational effectiveness be updated to allow education to make optimal use of new developments in ICT and to disseminate this knowledge to educational professionals.

There is a clear need for more information on other $21^{\text {st }}$ century skills and also on specific skills, and to continue monitoring basic skills via large-scale assessments. Recent initiatives to make use of new technologies to make large-scale assessments more continuous and authentic perhaps offer the promise that they can in time be integrated in a fruitful way directly into the learning process. The results of these initiatives warrant our close attention, but whatever their outcome is, it is clear that there is a need for more authentic, formative assessment methods in schools. There are already clear insights on the conditions under which formative assessment methods can be effective, but these need to be developed more in relation to new technologies currently emerging which create new possibilities and also new challenges in this area. It is far from clear that schools are equipped to deal with these challenges, raising the risk that what could be potentially a boon can end up as a burden on schools. Here as well, further professionalization of the teaching profession is desirable. As a general point we caution against the risk that assessment comes to be seen by students, teachers, schools or policymakers too much as a contest and too little as a means to gain a better understanding of the strong and weak points of their education. 
The Netherlands currently performs well on indicators of basic skill levels as well as in terms of educational attainment, but there are some concerns that we may not be doing quite so well at the top of the skills distribution. There are competing demands on education to simultaneously deal with the challenges of producing intellectual excellence for innovation and economic growth while at the same time making sure as few people as possible fall out of the educational boat and also maintaining high quality standards for the large middle group who are neither dunce nor genius but form the backbone of our economy and society. These competing demands are made more urgent by the increasing pressure on education budgets and hard choices will need to be made. Because we are approaching a point of diminishing returns for the relatively small top and bottom groups, in our view the focus in further improving education along the lines sketched above should be aimed primarily at the much larger middle group who make up $85 \%$ of the youth cohort.

In conclusion, much is expected of education to help prepare our society for the great changes taking place in the $21^{\text {st }}$ century, in a time that it is facing many challenges of its own in terms of dealing with the consequences of demographic shifts in student and teacher populations and increased diversity. With so much to be done there is no time to lose. 


\section{Literature}

Allen, J. and C. Meng, (2010) Voortijdige schoolverlaters: Aanleiding en gevolgen, ROAR-2010/9, Researchcentrum voor Onderwijs en Arbeidsmarkt, Maastricht.

Allen. J. and R. Van der Velden (2005) The Role of Self-Assessment in Measuring Skills, REFLEX Working paper 2, Researchcentrum voor Onderwijs en Arbeidsmarkt, Maastricht.

Autor, D. (2010) U.S. Labor Market Challenges over the Longer Term, October 2010, paper prepared for the Federal Reserve Board of Governors.

Becker, G.S. (1962), Investment in Human Capital: A Theoretical Analysis, In: Journal of Political Economy, University of Chicago Press, vol. 70, pages 9.

Beller, M. (2011). Technologies in Large-Scale Assessments: New Directions, Challenges and Opportunities, presentation at International Large-Scale Assessment Conference, March 16-18, 2011 ETS, Princeton, NJ.

Black, P. and D. Wiliam (1998), Inside the black box: Raising standards through classroom assessment. Phi Delta Kappan, 80(2): 139-149.

Borghans, L., R. Van der Velden, C. Büchner, J. Coenen and C. Meng (2008), Het meten van onderwijskwaliteit en de effecten van recente onderwijsverniewingen, In: Commissie Parlementair Onderzoek Onderwijsvernieuwingen, Tijd voor Onderwijs, Deelrapport IV, Den Haag: SDU, pp. 3-114.

Carroll, J.B. (1993). Human cognitive abilities: A survey of factor-analytic studies. New York: Cambridge University Press..

Cattell, R.B. (1987). Intelligence: Its structure, growth, and action. New York: Elsevier.

Coenen, J., G. Ramaekers and R. Van der Velden (forthcoming), De waarde van MBO-4 opleidingen op de arbeidsmarkt, Researchcentrum voor Onderwijs en Arbeidsmarkt, Maastricht.

Coenen, J., C. Meng and R. Van der Velden (2011) Schoolsucces van jongens en meisjes in het HAVO en VWO: waarom meisjes het beter doen, ROA-R-2011/2, Researchcentrum voor Onderwijs en Arbeidsmarkt, Maastricht.

Commissie Toekomstbestendig Hoger Onderwijs Stelsel (Commissie Veerman) (2010), Differentiëren in drievoud: omwille van kwaliteit en verscheidenheid in het hoger onderwijs.

Cowie, B., and B. Bell (1999), A model of formative assessment in science education, Assessment in Education, 6: 101-116. 
Cunha, F and J. Heckman (2007), The Technology of Skill Formation, American Economic Review, 97, 2, pp. 31-47.

Denktank Leren en Werken (2009), Tijd voor ontwikkeling: Advies van de Denktank Leren en Werken over het stimuleren van een leven lang leren in Nederland, Den Haag, Ministeries van Onderwijs, Cultuur en Wetenschap en Sociale Zaken en Werkgelegenheid.

Dronkers, J. (2010), Positieve maar ook negatieve effecten van etnische diversiteit in scholen op onderwijsprestaties? Een empirische toets met internationale PISA-data, Inaugurale rede, Universiteit Maastricht.

Fouarge, D and A. De Grip (2011), Depreciatie van menselijk kapitaal, ROA-R-2011/1, Researchcentrum voor Onderwijs en Arbeidsmarkt, Maastricht.

Goos, M., A. Manning and A. Salomons (2009), The Polarization of the European Labor, American Economic Review Papers and Proceedings, 99(2).

Hanushek, E. and L. Woessmann (2011), The economics of international differences in educational achievement, In: Handbook of the Economics of Education, Vol. 3, edited by Eric A. Hanushek, Stephen Machin, and Ludger Woessmann. Amsterdam: North Holland, 2011: 89-200.

Hinton, C. and K. Fischer (2010), Learning from the developmental and biological perspective, in OECD, The Nature of Learning: Using Research to Inspire Practice, OECD, Paris.

Johnson, L., Levine, A., Smith, R. and Stone, S. (2010). The 2010 Horizon Report. Austin, Texas: The New Media Consortium.

Jolles, J. (2007), Neurocognitieve ontwikkeling en adolescentie: enkele implicaties voor het onderwijs, Onderwijsinnovatie, maart 2007, 30-32.

Kennisnet (2010), Vier in Balans Monitor 2010, Ict in het onderwijs: de stand van zaken Levy, F. (2010), How technology changes demands for human skills, OECD Working Paper, No. 45, OECD, Paris.

Luyten, H. (2010), De kwaliteit van het Nederlandse nnderwijs uitgedrukt in achievement en attainment indicatoren, In: Scheerens, J., H. Luyten and J. Van Ravens (2010), Visies op onderwijskwaliteit, Universiteit Twente, Enschede.

Meng, C. (2006), Disipline-Specific or Academic? Acquisition, Role and Value of Higher Education Competencies, Thesis, Universiteit Maastricht.

Ministry of Education, Culture and Science, (2010), Key Figures 2005-2009. 
Minne, B., M. Rensman, B. Vroomen and D. Webbink (2007) Excellence for productivity? Den Haag: Centraal Planbureau.

Murray, S., Y. Clermont and M. Binkley (eds) (2005), Measuring Adult Literacy and Life Skills: New frameworks for Assessment, Statistics Canada, Ottawa, Catalogue No. 89-552-MIE, No. 13.

Onderwijsraad (2007), Doorstroom en talentontwikkeling: Onderwijs voor 12-18-jarigen, Verkenning, Den Haag, Onderwijsraad.

O'Reilly, T. and Sheehan, K. M. (2008). Cognitively based assessment of, for and as learning: a $21^{\text {st }}$ century approach for assessing reading competency. ETS internal research report.

OECD (2004), Problem Solving for Tomorrow's World: First Measures of CrossCurricular Competencies from PISA 2003, OECD, Paris.

OECD (2008), Higher Education to 2030, Volume 1, Demography, OECD, Paris.

OECD (2009) Higher Education to 2030, Volume 2, Globalization, OECD, Paris.

OECD (2010a) The Nature of Learning: Using Research to Inspire Practice, OECD, Paris.

OECD (2010b), Are the New Millennium Learners Making the Grade? Technology Use and Educational Performance in PISA 2006, OECD, Paris.

Reich (1992), The work of nations. Preparing ourselves for the $21^{\text {st }}$ century capitalism, New York: Vintage Books.

Ritzen, J. (2011) Large Scale Assessments as Change Agents, presentation at International Large-Scale Assessment Conference, March 16-18, 2011 ETS , Princeton, NJ.

ROA (2009), De arbeidsmarkt naar opleiding en beroep tot 2014, ROA-R-2009/5, Researchcentrum voor Onderwijs en Arbeidsmarkt, Maastricht.

Rychen, D.S. and L.H. Salganik (eds.), (2001) Defining and selecting key competencies, Göttingen, Germany: Hogrefe \& Huber.

Rychen, D.S. and L.H. Salganic (eds.) (2003), Key Competences for a Successful Life and a Well-functioning Society, Göttingen: Hogrefe \& Huber.

Scheerens, J., H. Luyten and J. Van Ravens (2010), Visies op onderwijskwaliteit, Universiteit Twente, Enschede.

Schifferes, S. (2007) Globalisation shakes the world, BBC Online.

Schleicher, A. (2008), PIAAC, A new strategy for assessing adult competencies, International Review of Education, DOI 10.1007/s11159-008-9105-0. 
Schulz, Wolfram, John Ainley Julian Fraillon David Kerr Bruno Losito (2010), Initial Findings from the IEA International Civic and Citizenship Education Study, Amsterdam: IEA.

Slavin, R.E. (2010) Co-operative learning: what makes group-work work? in OECD, The Nature of Learning: Using Research to Inspire Practice, OECD, Paris.

Thorn, W. (2009), International Adult Literacy and Basic Skills Surveys in the OECD Region, OECD Working Paper no. 26, OECD, Paris.

Van der Vleuten, C. (1996), Beyond intuition, Inaugurale rede, Universiteit Maastricht.

Van Deursen, A. (2010), Internet Skills: Vital Assets in an Information Society, Thesis University of Twente.

Van Dijk, J. (2005). The deepening divide. Inequality in the information society. London: Sage Publications.

Voogt J. and Pareja Roblin, N. (2010) $21^{\text {st }}$ Century Skills: Discussienota, Universiteit Twente: Enschede.

Weinert, F.E. (2001). Concept of competence: A conceptual clarification. In D.S. Rychen and L.H. Salganik (eds.), Defining and selecting key competencies (pp. 45-65). Göttingen, Germany: Hogrefe \& Huber.

Wiliam, D. (2010) The role of formative assessment in effective learning environments, in OECD, The Nature of Learning: Using Research to Inspire Practice, OECD, Paris. Zucker, A. and D. Light (2009), Laptop Programs for Students, Science, 323, 82-85. 